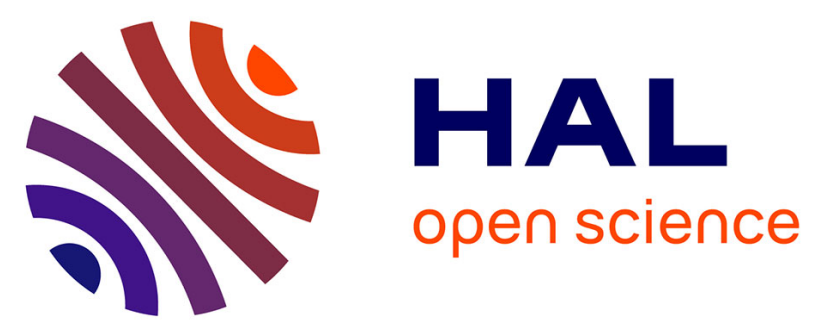

\title{
Reduction of Ln 2 Ti 2 O7 Layered Perovskites: A Survey of the Anionic Lattice, Electronic Features, and Potentials
}

\author{
Tanguy Pussacq, Houria Kabbour, Silviu Colis, Hervé Vezin, Sébastien
} Saitzek, Olivier Gardoll, Cédric Tassel, Hiroshi Kageyama, Christel Laberty

Robert, Olivier Mentré

\section{To cite this version:}

Tanguy Pussacq, Houria Kabbour, Silviu Colis, Hervé Vezin, Sébastien Saitzek, et al.. Reduction of Ln 2 Ti 2 O7 Layered Perovskites: A Survey of the Anionic Lattice, Electronic Features, and Potentials. Chemistry of Materials, 2017, 29 (3), pp.1047-1057. 10.1021/acs.chemmater.6b03808 . hal-01446009

\section{HAL Id: hal-01446009 https://hal.sorbonne-universite.fr/hal-01446009}

Submitted on 25 Jan 2017

HAL is a multi-disciplinary open access archive for the deposit and dissemination of scientific research documents, whether they are published or not. The documents may come from teaching and research institutions in France or abroad, or from public or private research centers.
L'archive ouverte pluridisciplinaire HAL, est destinée au dépôt et à la diffusion de documents scientifiques de niveau recherche, publiés ou non, émanant des établissements d'enseignement et de recherche français ou étrangers, des laboratoires publics ou privés. 


\title{
Reduction of $\mathrm{Ln}_{2} \mathrm{Ti}_{2} \mathrm{O}_{7}$ layered perovskites: a survey of the anionic Lattice, Electronic Features, and Potentialities
}

\author{
Tanguy Pussacq ${ }^{[a]}$, Houria Kabbour ${ }^{[a]}$, Silviu Colis ${ }^{[b]}$, Hervé Vezin ${ }^{[c]}$, Sébastien Saitzek ${ }^{[a]}$, \\ Olivier Gardoll ${ }^{[a]}$, Cédric Tassel ${ }^{[\mathrm{d}]}$, Hiroshi Kageyama ${ }^{[\mathrm{d}]}$, Christel Laberty Robert ${ }^{[\mathrm{e}]}$, Olivier \\ Mentré*[a]
}

[a] Univ. Lille, CNRS, ENSCL, Centrale Lille, Univ. Artois, UMR 8181 - UCCS - Unité de Catalyse et de Chimie du Solide, F-59000 Lille, France

[b] IPCMS, Strasbourg-France

[c] LASIR, UMR-CNRS 8516, Université de Lille1, Lille, Villeneuve d'Ascq C5-59655 France

[d] Department of Energy and Hydrocarbon Chemistry, Graduate School of Engineering, Kyoto University, Nishikyo-ku, Kyoto 615-8510, Japan

[e] Sorbonne Université, UPMC Univ. Paris 06, CNRS UMR 7574, Collège de France, LCMCP, 11 Place Marcelin Berthelot , 75005 Paris , France

\footnotetext{
* Corresponding author: olivier.mentre@ensc-lille.fr
} 


\section{Abstract}

The reduction of the layered perovskites $\mathrm{Ln}_{2} \mathrm{Ti}_{2} \mathrm{O}_{7}(\mathrm{LnTO}$, with lanthanide $\mathrm{Ln}=\mathrm{La}, \mathrm{Pr}, \mathrm{Nd})$ was studied with the aim to shift the UV photocalytic activity for water splitting in the visible range by $\mathrm{Ti}^{3+}$ donor doping. For all phases, after reduction by $\mathrm{CaH}_{2}$, the absorbance is extended beyond the UV-vis region, giving rise to a gap-like edge in the mid-infrared at $\sim 0.4 \mathrm{eV}$ with a dark coloration of the samples. When the precursor with $\mathrm{Ln}=\mathrm{La}$ was reduced under high temperature $\mathrm{H}_{2}$ flow, we found a progressive nanotexturation down to $300 \mathrm{~nm}$, which is responsible for a degree of $\mathrm{Ti}^{3+}$ segregation at the surface. Magnetic measurements, thermal analysis and powder neutron diffraction (PND) reveal that the sample reduced by both routes have a similar amount of anion vacancy with $\delta=0.27$ (in $\mathrm{La}_{2} \mathrm{Ti}_{2} \mathrm{O}_{7-\delta}$ ). It represents a limited topotactic reduction stage, prior to the reconstructive reduction into $\mathrm{La}_{5} \mathrm{Ti}^{+3.8}{ }_{5} \mathrm{O}_{17}$ observed in more sever reducing conditions. For the sample reduced by $\mathrm{CaH}_{2}$, a minor amount of hydride appears to be incorporated ( $0.02 \mathrm{H}$ per $\mathrm{FU})$, with a $\mathrm{Ti}^{3+}---\mathrm{H}^{-}$bonding observed by HYSCORE electron paramagnetic resonance (EPR) and density functional theory (DFT) calculations. Preliminary electrocatalysis tests show a promising anodic activity for water splitting hydrogen evolution with a voltage onset as low as $0.6 \mathrm{~V} v s$. RHE.

\section{Introduction}

Herein, the recent incorporation of significant amounts of hydride anions in the $\mathrm{BaTiO}_{3-\mathrm{x}} \mathrm{H}_{\mathrm{x}}$ perovskite $(x \leq 0.6)$ by $\mathrm{CaH}_{2}$ reduction at moderate temperature ${ }^{1}$ was a source of inspiration for further studies, in trying to diversify the host systems for reduction of $\mathrm{Ti}^{4+}$ into mixed valence $\mathrm{Ti}^{3+} / \mathrm{Ti}^{4+}$ oxyhydrides. Similar reduction for $\mathrm{ATiO}_{3}$ epitaxial thin films $(\mathrm{A}=\mathrm{Ca}, \mathrm{Sr}, \mathrm{Ba})$ led to metallic $\mathrm{ATi}(\mathrm{O}, \mathrm{H})_{3}$ phases, ${ }^{2}$ while for a low hydride content a semiconducting state can also be reached. ${ }^{3}$ We recall that upon reduction of Ruddlesden-Popper (RP) phases, $\mathrm{Ca}_{n+1} \mathrm{Ti}_{n} \mathrm{O}_{3 n+1-\delta}$, under flowing $\mathrm{H}_{2}$ also gives metallicity even with tiny oxygen deficiency $(\delta<$ $0.001)$ which provides activated electrons from the conduction band. ${ }^{4}$ This ability for tuning the bandgap in mixed $\mathrm{Ti}^{3+} / \mathrm{Ti}^{4+} \mathrm{RP}$ systems in a controlled manner offers promising potentials for various photo-electronic properties.

An extra opportunity is given to the $A_{n} B_{n} O_{3 n+2}$ series $\left(n=\right.$ integer) ${ }^{5,6}$ composed also of perovskite-like blocks separated by $A$ cations. The perovskite layer $n$ extends from 2 to 6 and $n \rightarrow \infty$ corresponds to the three-dimensional standard perovskite $\mathrm{ABO}_{3}$. For lanthanide $(\mathrm{Ln})$ titanates, the increase of $\mathrm{n}$ from $4\left(\mathrm{Ln}_{2} \mathrm{Ti}^{4+}{ }_{2} \mathrm{O}_{7}\right)$ to $5\left(\mathrm{Ln}_{5} \mathrm{Ti}^{3.8^{+}}{ }_{5} \mathrm{O}_{17}\right)$ and then to $\mathrm{n} \rightarrow \infty$ $\left(\mathrm{LnTi}^{3+} \mathrm{O}_{3}\right)$ is accompanied by a progressive reconstructive titanium reduction. The $n=4$ member $\left(\mathrm{Ln}_{4} \mathrm{Ti}_{4} \mathrm{O}_{14}\right.$, i.e. $\left.\mathrm{Ln}_{2} \mathrm{Ti}_{2} \mathrm{O}_{7}\right)$ cover two structural types depending on the $\mathrm{Ln}$ ionic radius. The layered perovskite structure is thermodynamically stable for $L n=L a, \operatorname{Pr}, N d\left(r_{X I I}=\right.$ 
1.36 - $1.27 \AA$ ). Although the pyrochlore structure is preferred for smaller $\mathrm{Ln}^{3+}$ ions, the layered perovskite (ferroelectric) structure can be extended up to $\mathrm{Gd}_{2} \mathrm{Ti}_{2} \mathrm{O}_{7}$ by substrate constraints in epitaxial thin films. ${ }^{7}$ At the pyrochlore side, the $\mathrm{CaH}_{2}$ reduction for small $\mathrm{A}^{3+}$ ions (e.g. $\mathrm{Y}, \mathrm{Lu}$, $\mathrm{Yb}$ ) topochemically leads to reduced pyrochlore $\mathrm{AB}_{2} \mathrm{O}_{7-\delta}$ with an $\mathrm{A} / \mathrm{B}$ anti-site disorder and phase separation. ${ }^{8,9}$ For bigger $A^{3+}$ ions (e.g. $\mathrm{Sm}$, Eu), the transformation into $\mathrm{ABO}_{3}$ perovskite was reported, ${ }^{8}$ while more recent investigation of the reduction for Eu indicated the formation of perovskite oxyhydrides $\mathrm{EuTiO}_{3-x} \mathrm{H}_{x}(x \leq 0.3) .{ }^{10}$ To the best of our knowledge, no significant result has been obtained for layered perovskites. $\mathrm{La}_{2} \mathrm{Ti}_{2} \mathrm{O}_{7}$ is a ferroelectric compound well known for its high Curie-temperature, spontaneous polarization and dielectric constant $\left(T_{\mathrm{c}} \sim 1500{ }^{\circ} \mathrm{C}, \mathrm{Ps} \sim 5 \mu \mathrm{C} . \mathrm{cm}^{-2}, \varepsilon \sim 42-62\right) .{ }^{11}$ Tuning the gap of this compound while conserving the non-centrosymmetry is challenging. Undoped $\mathrm{La}_{2} \mathrm{Ti}_{2} \mathrm{O}_{7}$ has a wide bandgap of $3-4 \mathrm{eV}$, the magnitude of which depends on its microstructure, ${ }^{12}$ and it exhibits photocatalytic activity under UV irradiation. This material can also be used for $\mathrm{H}_{2}$ generation by water splitting ${ }^{13}$ for the degradation of volatile organic compounds ${ }^{14}$ and the photoreduction of metal ion such as $\mathrm{Cr}$ (IV). ${ }^{15} \mathrm{~A}$ further reduction of the gap into the visible light region is highly demanded and in fact this could be achieved by $\mathrm{Rh}^{3+}, \mathrm{Fe}^{3+}, \mathrm{Cr}^{3+}$ doping leading to $\mathrm{H}_{2}$ evolution from aqueous-methanol solution due to unfilled $3 \mathrm{~d}$ localized levels in the gap. ${ }^{16,17,18}$ Recently, it has been experimentally demonstrated that nitrogen-doped $\mathrm{La}_{2} \mathrm{Ti}_{2} \mathrm{O}_{7}$ nanosheets showed both significant visible light but also enhanced ultraviolet photocatalytic activity. ${ }^{19}$ Here, first principle calculations suggest that both $\mathrm{N}^{3-}$ host and oxygen vacancies act to narrow the bandgap by creation of a continuum band at the top of the valence band. Apart from aliovalent doping, introduction of only a small $\mathrm{Ti}^{3+}$ content in $\mathrm{La}_{2} \mathrm{Ti}_{2} \mathrm{O}_{7}$ has been reported using a combustion synthesis route. ${ }^{20}$ In our work, the LTO bandgap engineering was provided by using either solid hydride or $\mathrm{H}_{2}$ gas as reducing agents. Although both routes provided a maximal ratio of ca. $4 \%$ of oxygen vacancies upon topochemical reduction, contrasted microstructures have been obtained. This aspect will be discussed on the basis of the structure ability to accommodate anionic vacancies in that context. In addition, the weak $\mathrm{H}^{-}$incorporation using the solid route was analyzed by means of pulsed EPR, giving microscopic insights into the Ti---H bonding nature. Besides, precise characterizations of the reduced LTO forms and preliminary aptitudes for electro catalytic water splitting are demonstrated.

\section{Experimental and techniques}

Synthesis: Powder samples of $\mathrm{La}_{2} \mathrm{Ti}_{2} \mathrm{O}_{7}$ (LTO), $\mathrm{Nd}_{2} \mathrm{Ti}_{2} \mathrm{O} 7$ (NTO) and $\mathrm{Pr}_{2} \mathrm{Ti}_{2} \mathrm{O}_{7}$ (PTO) were prepared by solid state synthesis from a stoichiometric mixture of high purity binary oxides. As starting reagents, $\mathrm{La}_{2} \mathrm{O}_{3}\left(1.629 \mathrm{~g}, 99.9 \%\right.$, Alfa Aesar), $\mathrm{Nd}_{2} \mathrm{O}_{3}$ (1.522 g, 99.9\%, Reacton), $\mathrm{Pr}_{6} \mathrm{O}_{11}\left(1.702 \mathrm{~g}, 99.9 \%\right.$ Alfa Aesar) and $\mathrm{TiO}_{2}$ (0.799 g, 99\%, Fluka) were used. After grinding 
in an agate mortar, the mixture was calcined in an alumina crucible in air at $1350^{\circ} \mathrm{C}$ for a total time of $170 \mathrm{~h}(50 \mathrm{~h}+48 \mathrm{~h}+72 \mathrm{~h})$ with intermediate grinding steps in ethanol. The reduction via the hydride route was then conducted by grinding $\mathrm{La}_{2} \mathrm{Ti}_{2} \mathrm{O}_{7}(0.2889 \mathrm{~g}), \mathrm{Nd}_{2} \mathrm{Ti}_{2} \mathrm{O}$ (0.2946 g) or $\mathrm{Pr}_{2} \mathrm{Ti}_{2} \mathrm{O}_{7}(0.2906 \mathrm{~g})$ with $\mathrm{CaH}_{2}(0.15 \mathrm{~g})$, so as to have a molar $\mathrm{Ti} / \mathrm{H}$ ratio of $1 / 3$, in a glove box. The powder was then flame-sealed in an evacuated Pyrex or silica tube $\left(15 \mathrm{~cm}^{3}\right)$ at pressures below $1.10^{-2}$ Bar. The tubes were then heated at $550^{\circ} \mathrm{C}$ during $72 \mathrm{~h}$, reiterating the process until the powder turns black. Then, the product has been washed several times with a $0.1 \mathrm{M} \mathrm{NH}_{4} \mathrm{Cl} /$ methanol solution to remove excess $\mathrm{CaH}_{2}$ and $\mathrm{CaO}$ and dried in an oven at $100^{\circ} \mathrm{C}$.

The reduction via the hydrogen route was performed by firing $\mathrm{La}_{2} \mathrm{Ti}_{2} \mathrm{O}_{7}$ under flowing pure hydrogen gas in a tubular furnace during $12 \mathrm{~h}$ at a temperature of $1000^{\circ} \mathrm{C}$. The furnace was then switched off to rapidly cool the sample while preserving the hydrogen flow. This treatment was found to allow the best compromise between reduction and nondecomposition. Caution: for both treatments, using solid $\mathrm{CaH}_{2}$ or $\mathrm{H}_{2}$ flow, particular safely rules must be respected to avoid contact with air.

Diffraction: X-ray diffraction (XRD) patterns were collected using a Bruker AXS D8 Advance $\mathrm{X}$-ray diffractometer (radiation $\mathrm{Cu} \mathrm{Ka}=1.5418 \mathrm{~A}$ ) equipped with a fast detector type LynxEye using a copper anticathode and a secondary beam monochromator. The scanning rate was $0.02^{\circ}$ with the step time adapted for each sample. XRD data were also collected on the Synchrotron 11-BM beamline at the Advanced Photon Source (APS, Argonne National Laboratory) with a wavelength of $\lambda=0.4137 \AA$. High-resolution Powder Neutron Diffraction (PND) experiment was carried out at the ILL on the 3 T2 diffractometer, $\lambda=1.22 \AA$.

Elemental Analysis: the Elemental Analysis for the quantification of $\mathrm{C}, \mathrm{H}$ and $\mathrm{N}$ contents in LTO, LTO- $\mathrm{H}_{2}$ and LTO-CaH $\mathrm{H}_{2}$ samples were made on a HPLC analysis using a Chiralpak AD column (hexane/iPrOH $=90 / 10$, flow $=0.8 \mathrm{ml} / \mathrm{min}$ ).

Transmission electron Microscopy (TEM) experiments were carried out on a FEI Tecnai G220 microscope operating at an accelerating voltage of $200 \mathrm{kV}$ equipped with a $\mathrm{LaB}_{6}$ crystal. Prior to TEM observations, samples were deposited from ethanolic solution onto holey-carbon copper grids.

TPD/TCD and Thermal analysis: The amount of adsorbed hydrogen of the $\mathrm{La}_{2} \mathrm{Ti}_{2} \mathrm{O}_{7}-\mathrm{CaH}_{2}$ phase was evaluated by TPD using a Micromeritics Autochem 2920 apparatus coupled with a mass spectrometer Omnistar. $100 \mathrm{mg}$ of the reduced phase was outgassed under a helium flow of $40 \mathrm{~mL} \mathrm{~min}^{-1}$, while being heated from room temperature to $1023 \mathrm{~K}$ with a heating rate of $40 \mathrm{~K} \mathrm{~min}^{-1}$ before cooling to room temperature under He. Thermogravimetric analysis 
(TGA) on $\mathrm{Ln}_{2} \mathrm{Ti}_{2} \mathrm{O}_{7}$ after the hydridation treatment was carried out using a TGA 92-1600 SETARAM analyzer under flowing recomposed air $\left(20 \% \mathrm{O}_{2}\right.$ and $\left.80 \% \mathrm{~N}_{2}\right)$ or pure Argon, from room temperature to $1000{ }^{\circ} \mathrm{C}$, upon heating and cooling.

Infrared Spectroscopy: Infrared analysis was carried out using a Perkin-Elmer Spectrum 2 instrument equipped with a single reflection diamond module (ATR). IR spectra were recorded in the $400-4000 \mathrm{~cm}^{-1}$ range with a $4 \mathrm{~cm}^{-1}$ resolution.

XPS measurements: X-ray photoelectron spectroscopy (XPS) experiments were performed using an AXIS Ultra DLD Kratos spectrometer equipped with a monochromatized aluminum source $\left(\mathrm{Al} \mathrm{K} \mathrm{K}_{\alpha}=1486.7 \mathrm{eV}\right)$ and charge compensation gun. All binding energies were referenced to the $\mathrm{C} 1 \mathrm{~s}$ core level at $285 \mathrm{eV}$. Simulation of the experimental photo peaks was carried out using a mixed Gaussian/Lorentzian peak fit procedure according to the software supplied by CasaXPS.

Magnetic measurements: The magnetic characterizations $M(H)$ and $X^{-1}(T)$ were performed using a MPMS SQUID-VSM (Quantum Design) magnetometer in a temperature and field range of $1.8-300 \mathrm{~K}$ and $0-5 \mathrm{~T}$, respectively. The temperature dependence variation of the magnetization was carried out under various magnetic fields after cooling the sample in a field (FC: field cooling) or in zero field (ZFC: zero field cooling).

EPR measurements: X-band measurements were performed at $4 \mathrm{~K}$ with a Brüker ELEXYS E580 equipped with a cryofluid-free cryostat. Continuous wave (CW) spectra were recorded using respectively $1 \mathrm{~mW}$ microwave power and $5 \mathrm{G}$ of amplitude modulation. In a HYSCORE (hyperfine sublevel correlation spectroscopy) experiment, characterized by the four pulse sequence $\pi / 2-\tau-\pi / 2-t 1-\pi-t 2-\pi / 2-\tau$-echo, the first part $(\pi / 2-\tau-\pi / 2)$ of the sequence creates nuclear coherences (coherent superpositions of $m_{1}$ states) in each $m_{s}= \pm 1 / 2$ state. The $\pi$ pulse transfers each nuclear coherence from one $m_{s}$ state to the other, and the last $\pi / 2$ pulse transfers all nuclear coherences to the electron coherence (coherent superposition of $\mathrm{m}_{\mathrm{s}}=$ $\pm 1 / 2$ states) for detection.

Density functional theory (DFT) calculations were performed using the Vienna ab initio simulation package (VASP). ${ }^{21}$ The calculations were carried out within the generalized gradient approximation (GGA) for the electron exchange and correlation corrections using the Perdew-Wang (PW91) functional and the frozen core projected wave vector method. ${ }^{22,23}$ The full geometry optimizations on the three studied models (1- precursor oxide, 2oxyhydride and 3- lacunar) were carried out using a plane wave energy cutoff of $550 \mathrm{eV}$ and a set of $5 \times 3 \times 7$ k-points. All structural optimizations converged with residual HellmanFeynman forces on the atoms smaller than $0.03 \mathrm{eV} / \AA$. The relaxed structures were used for calculations of the electronic structure. In that purpose, we employed a plane wave energy 
cutoff of $400 \mathrm{eV}$, an energy convergence criterion of $10^{-6} \mathrm{eV}$ and a set of $10 \times 6 \times 14$ k-points for all models. For the oxyhydride and the lacunar models (presence of $\mathrm{Ti}^{3+}$ ), we employed $G G A+U$ calculations (DFT plus on-site repulsion $U)^{24}$ in order to describe the electron correlation associated with the $3 \mathrm{~d}$ states of Ti. An effective on-site repulsion value $U_{\text {eff }}=U-J$ $=3 \mathrm{eV}$ was used.

\section{Results and Discussion}

In order to explore the different possibilities of topotactic reductions, layered perovskite $\mathrm{Ln}_{2} \mathrm{Ti}_{2} \mathrm{O}_{7}$ compounds were reacted either by mixing with solid $\mathrm{CaH}_{2}$ or $\mathrm{NaH}$, or flowing $\mathrm{H}_{2}$ $(100 \%)$. The reactivity with metal hydride was tested with variation conditions using the following parameters: time (72 $\mathrm{h}$ to $144 \mathrm{~h})$, temperature $\left(350^{\circ} \mathrm{C}\right.$ to $\left.650^{\circ} \mathrm{C}\right)$ and stoichiometry between the hydride and the pristine compound ( $\mathrm{H} / \mathrm{Ti}$ ratio of 1 to 6$)$. Using $\mathrm{NaH}$, depending on the temperature and reaction time, we obtained either unreacted compounds, either decomposed binary oxides. The highest temperature and/or hydride reactant amount lead to partial or complete decomposition of the phase into binary oxides $\left(\mathrm{La}_{2} \mathrm{O}_{3}, \mathrm{TiO}_{2}\right)$, amorphization and formation of phases such as $\mathrm{La}_{5} \mathrm{Ti}_{5} \mathrm{O}_{17}$ or $\mathrm{La}_{4} \mathrm{Ti}_{3} \mathrm{O}_{12}$. This result highlights the further reconstructive reduction into the $n=5 A_{n} B_{n} O_{3 n+2}$ mentioned in the introduction. Figure S1a shows selected XRD patterns after various reaction conditions. In order to analyze the topochemical accommodation of vacancies keeping the original LnTO crystal structure, the best selected synthesis parameters were $550{ }^{\circ} \mathrm{C}, 144 \mathrm{~h}$ and use of $\mathrm{CaH}_{2}$ with a $\mathrm{H} / \mathrm{Ti}$ ratio of 3 . So we could obtain reduced phases as shown by drastic color changes leading to nearly single phase with limited loss of crystallinity. Using a hydrogen flow, the temperature was increased until the color darkens significantly. From our screening, the ideal conditions are $\mathrm{T}=1000{ }^{\circ} \mathrm{C}$ and $\mathrm{t}=12 \mathrm{~h}$. The phase could be partially/fully decomposed at higher temperature. A surficial decomposition responsible of the color change could not be excluded at this stage. The respective samples will be denoted LTO-CaH $\mathrm{H}_{2}$ and $\mathrm{LTO}-\mathrm{H}_{2}$ in the following.

Physico-chemical features upon reduction: Analysis of the diffraction patterns of the parent (LTO) and reduced phases $\left(\mathrm{LTO}-\mathrm{H}_{2}\right.$ and $\left.\mathrm{LTO}-\mathrm{CaH}_{2}\right)$ (Figure 1) indicates a loss of crystallinity dependent on the reduction pathway. The Bragg peaks of the different samples follow the same extinction rules and show the conservation of the symmetry of LTO after reduction, as confirmed for $\mathrm{LTO}-\mathrm{CaH}_{2}$ after PND data treatment. For $\mathrm{LTO}-\mathrm{CaH}_{2}$, the splitting of the peaks typical of the monoclinic lattice (space group P112 ${ }_{1}$ ) is observed using the synchrotron radiation. The lattice parameters and diffracting particle $\beta_{\text {size }}$ were determined 
after XRD-profile fitting using the Cox-Hasting function implemented in the Fullprof suite. ${ }^{25}$ The instrumental profile was determined using a $\mathrm{LaB}_{6}$ standard.

Table 1 gives the refined lattice parameters for various samples and radiation sources. The evolution between LTO and LTO-CaH $\mathrm{H}_{2}$ is minor while only LTO- $\mathrm{H}_{2}$ shows a detectable cell contraction. However this latter should be considered with precaution, taking into account the relative evolution of the microstructure. Indeed, the as-prepared LTO (white powder) particle size was refined to $\beta_{\text {size }}=5474(8) \AA$ (i.e. $\sim 5500 \AA$ ), in agreement with a well crystalline submicronic powder, see fig.1a. LTO-CaH $\mathrm{C}_{2}$ which is black, shows a strong size broadening effect for all peaks leading to a crystal size of 833.6(8) $\AA$, (fig1.b). It validates the fragmentation of initial particles under the $\mathrm{CaH}_{2}$ treatment, see the TEM image (fig. 1d). The peak broadening sometimes reported for oxyhydride perovskites ${ }^{10}$ often results from the $\mathrm{H}$ distribution. In reduced LTO, the inhomogeneous distribution of vacancies/H is also probable but the fragility of the LTO structure during the reduction process is the main driving parameter for the nanometrization due to a limited accommodation of vacancies. We recall that most stable reduced phases exist via reconstructive transformations, maybe already on the run. Note that a partial decomposition into $\mathrm{La}_{5} \mathrm{Ti}^{3.8+}{ }_{5} \mathrm{O}_{17}(\mathrm{n}=5$ octahedra perovskite layers) and $\mathrm{RP} \mathrm{La}_{4} \mathrm{Ti}_{3} \mathrm{O}_{12}$ was detected in more aggressive conditions, see fig. S1. It proves that prior to the reconstructive reduction, the topochemical reduction is allowed while the structure suffers instability and local decomposition. All electron diffraction patterns obtained for reduced LTO samples show evidence for superposition of disoriented domains due to this drastic size reduction, see Figure $S 1 \mathrm{~b}$. It is such that the searching of eventual $n=5$ intergrown domains by HREM was not possible. Then, as discussed later about magnetic properties, a certain degree of surficial segregation of reduced species is expected. Additionally, the refinement is imperfect, due to diffuse shoulder at the bottom of some peaks and asymmetric broadening that occurs at high or low angles depending on the reflections. This effect is clearly evidenced on the high resolution XRD data (synchrotron radiation, 11BM, Argonne Laboratory, $\lambda=0.414 \AA$ ) as shown by blue arrows on the figure 1e by drastic asymmetric broadening effects that we did not attempt to model. The diffuse shoulder should arise from an uneven distribution of diffracting particle sizes and the asymmetric broadening presumably indicates local intergrowth defects between distinct perovskite blocks, commonly found after reduction, see the reduced $\mathrm{RP} \mathrm{Nd}_{4} \mathrm{Ni}_{3} \mathrm{O}_{8}$ prepared under flowing hydrogen. ${ }^{26}$

This type of irregular intergrowth of the layers has also been reported after the reduction $\mathrm{La}_{3} \mathrm{Ni}_{2} \mathrm{O}_{7-\mathrm{x}}$ into $\mathrm{La}_{3} \mathrm{Ni}_{2} \mathrm{O}_{6.35}{ }^{27}$ Here again, the observation of $\mathrm{n}=5$ octahedra thick blocks $\left(\mathrm{La}_{5} \mathrm{Ti}_{5} \mathrm{O}_{17}\right.$ with intrinsic $\mathrm{Ti}^{3+}$ distribution) in more reducing conditions comfort the 
defected state of $\mathrm{LTO}^{-\mathrm{CaH}_{2}}$. After treatment under $\mathrm{H}_{2}$ gas flow at $1000^{\circ} \mathrm{C}$, the broadening of XRD peaks is intensified. It results in a pale blue nano powder with an average size of 294.2(7) $\AA$ ( $300 \AA)$, see fig.1c, d. However the peaks preserve a symmetrical shape excluding a significant phase transformation into related members of the $A_{n} B_{n} O_{3 n+2}$ series.

a)

b)
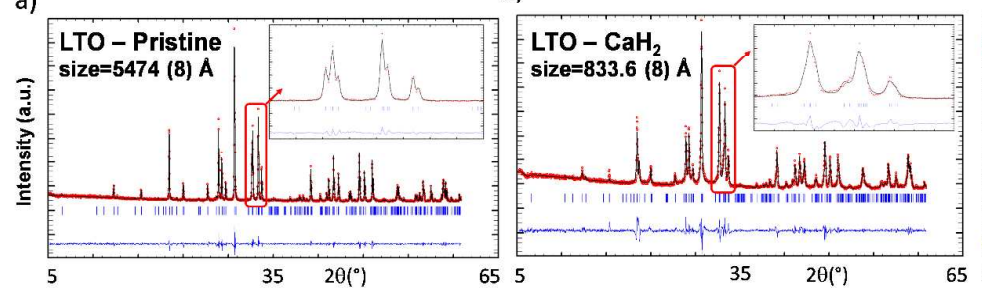

d)
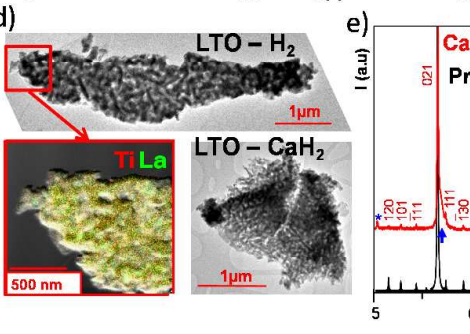

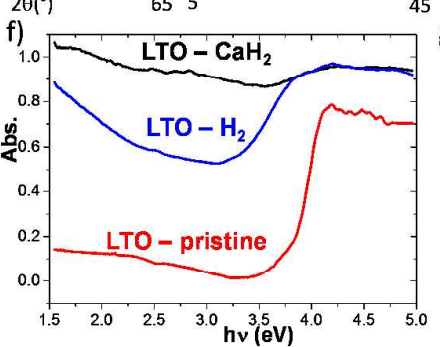

c)

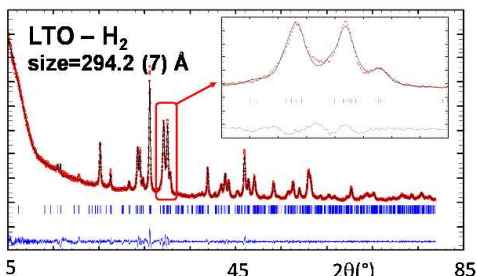
${ }^{45}$

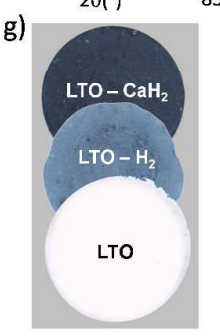

Fig 1: $(a, b, c)$ Profile fitting and crystal size for $L T O, L T O-C a H_{2}$ and $L T O-H_{2}$ with a progressive broadening of $X R D$ peaks. The refined lattice parameters are a=7.8120(1) $\AA$, $b=13.0144(2) \AA, c=5.5472(1) \AA, \quad \beta=98.6318(8)^{\circ} ; a=7.8159(5) \AA, b=13.0064(9) \AA, c=$ $5.5480(3) \AA, \beta=98.5866(3)^{\circ}$ and $a=7.8076(3) \AA, b=12.9914(6) \AA, c=5.5299(3) \AA, \beta=$ 98.551(3) ${ }^{\circ}$ respectively. d) nano-fragmentation observed from with Ti/La EDS mapping for $\mathrm{CaH}_{2}$ showing the homogeneous composition. e) Synchrotron XRD data (Argonne Source $11 B M, \lambda=0.42 \AA$ ) with asymmetric broadening pointed by blue arrows. f) UV-Vis absorption curves for the LTO-series. g) Color variations after reducing treatments.

Besides the size reduction, the color changes show major modifications of the electronic structure, analyzed hereafter by the UV/vis spectroscopy (Figure 1g). LTO shows a bandgap of $3.63 \mathrm{eV}$, from the Tauc plot after Kubelka-Munk transformation $(\alpha \mathrm{hv})^{1 / 2}$ for indirect bandgap (LTO case), see Fig. 1f. For the pale-blue $\mathrm{LTO}-\mathrm{H}_{2}$, in addition to the reminiscence of the original transitions, the absorption is extended to the visible light region due to the formation of $\mathrm{Ti}^{3+}$ extra electrons in defect levels. The estimated bandgap is reduced to 2.02 $\mathrm{eV}$ from Tauc plots, see fig.1f. For the dark-colored $\mathrm{LTO}^{-\mathrm{CaH}_{2}}$, a quasi-continuous absorption is observed in the UV-vis range which is typical of highly reduced titanates such as $\mathrm{TiO}_{2-x}{ }^{28}$ or $\mathrm{BaTiO}_{3-\mathrm{x}}{ }^{29}$. Similarly to what has been reported for aliovalent doped $\mathrm{Ti}_{1-x} \mathrm{M}_{\mathrm{x}} \mathrm{O}_{2-\delta}$, electron-doping populates defect levels below the conduction band and shifts the bandgap edge deep into the forbidden gap (Urbach tail). ${ }^{30}$ Similar effects have been observed after treating $\mathrm{Nd}_{2} \mathrm{Ti}_{2} \mathrm{O}_{7}$ (NTO) and $\mathrm{Pr}_{2} \mathrm{Ti}_{2} \mathrm{O}_{7}$ (PTO) with $\mathrm{CaH}_{2}$. Their UV-Vis spectra (pristine phases and after $\mathrm{CaH}_{2}$ treatment), are given in Figure S2. Here again, the as-prepared 
compounds display the expected bandgaps, (3.73 eV for NTO and $2.99 \mathrm{eV}$ for PTO), while the absorption is continuous in the full UV/visible range, after reduction by hydrides. We also observe the occurrence of $\mathrm{f} \rightarrow \mathrm{f}$ electronic transitions from the paramagnetic $\mathrm{Nd}^{3+}$ and $\mathrm{Pr}^{3+}$ ions. For the three hydrides, clues for low energy electronic transitions at $0.43 \mathrm{eV}$ (i.e. 3500 $\mathrm{cm}^{-1}$ ) are found on IR spectra after comparison with the pristine phases, see figure 2 . Although the transmission step for the three $\mathrm{LnTO}-\mathrm{CaH}_{2}$ samples should be interpreted with precaution, it could picture the gap narrowing by donor/shallow levels at the bottom of the conduction band. It suggests a narrow-gap semiconducting behavior, although we have not been able to measure a reasonable electric conductivity on densified pellets (compacity $\sim 68 \%$ ). Both blocking grain boundaries and inhomogeneities of the distribution of vacancies may be involved. 

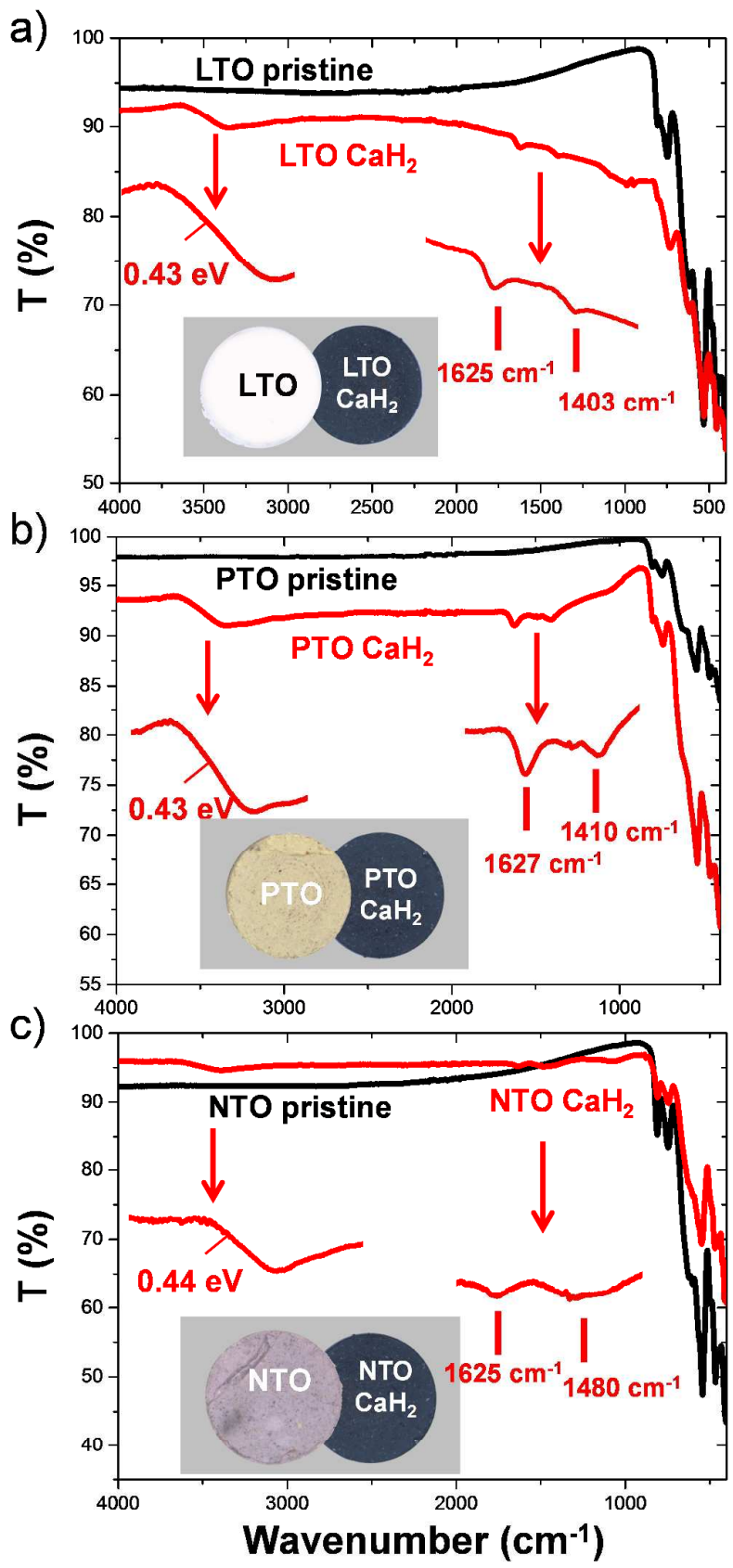

Figure 2 : Infrared spectra for a) $L T O$ and $L T O-\mathrm{CaH}_{2}$. b) PTO and PTO-CaH $\mathrm{C}_{2}$ c) NTO and NTO-CaH ${ }_{2}$. The zoom in red highlights the gap-like edge at $\sim 0.4 \mathrm{eV}$ and extra band due to partial hydridation (see text).

Hydrides against vacancies: Focusing on the LTO based compounds, besides the reduction rate, one important insight concerns the incorporation or not of hydrides ions in LTO-CaH ${ }_{2}$, especially taking into account the existence of fourteen independent oxygen positions in the monoclinic LTO crystal structure, with specific reactivities towards $\mathrm{H}^{-}$. Although $\mathrm{LTO}-\mathrm{CaH}_{2}$ was washed/stirred in $\mathrm{NH}_{4} \mathrm{Cl} /$ methanol and dried in oven, its preliminary TGA under flowing 
argon (see figure S3) shows an important mass loss (>13\%) until $650^{\circ} \mathrm{C}$. This mainly stems from residual solvent absorbed on the nanosized grains. Around $\mathrm{T}=400^{\circ} \mathrm{C}$, a second step is assigned to the removal of various surficial species, including a weak but undoubtful $\mathrm{H}_{2}$ peak $(\mathrm{m} / \mathrm{e}=2)$ detected by mass spectrometry. The second abrupt mass loss around $650^{\circ} \mathrm{C}$ corresponds to the departure of the carbonate species $(\mathrm{m} / \mathrm{e}=44)$. To remove most of the solvent and undesirable species, samples were heated overnight at $100^{\circ} \mathrm{C}$ in secondary vacuum. After combustion in a commercial elementary analyzer chamber, a significant decrease of the carbon and hydrogen content was observed, reaching values close to those for the pristine LTO and LTO- $\mathrm{H}_{2}$, see Table S4. Thus, the contamination by surficial carbonates is significant, and emphasized by nanostructures. Similarly the nitrogenabsorption is rather important in any cases (wt\% between 0.64 and 0.94 ). For $\mathrm{LTO}^{\mathrm{C}} \mathrm{CaH} \mathrm{H}_{2}$ the amount of hydrogen possibly associated to hydride is hard to distinguish due to residual water and solvent traces. It was accurately estimated by temperature programmed desorption (TPD) using a thermal conductivity detector (TCD), coupled with mass spectrometry under flowing $\mathrm{Ar}$, see Figure $3 \mathrm{a}$, b. For $\mathrm{LTO}-\mathrm{CaH}_{2}$, the TCD signal shows first the water removal $(\mathrm{m} / \mathrm{e}=18)$ between $100^{\circ} \mathrm{C}$ and $250^{\circ} \mathrm{C}$ in good agreement with the preliminary TGA. The broad desorption above $440^{\circ} \mathrm{C}$ is assigned to $\mathrm{CO}$ and/or $\mathrm{N}_{2}(\mathrm{~m} / \mathrm{e}=18)$ and a later $\mathrm{H}_{2}(\mathrm{~m} / \mathrm{e}=2)$ removal. At this temperature the system also absorbs the residual oxygen impurity of the He flow (<0.1 ppm). The quantification of hydrogen was performed after injection of 5 pulses of hydrogen and calibration of both TCD and mass spectroscopy signals (see Supplementary S5). The integration and scaling of the hydrogen peak gives coherent but very weak released hydrogen $\left(\mathrm{H}_{2}\right)$ amount of $0.00357 \mathrm{mmol} / \mathrm{g}$ (TCD) and $0.00319 \mathrm{mmol} / \mathrm{g}$ (mass spectroscopy), see the inset of Figure $3 \mathrm{~b}$. It leads to the formula $\mathrm{La}_{2} \mathrm{Ti}_{2} \mathrm{O}_{7-x} \mathrm{H}_{0.02}$. The HYSCORE-EPR study presented below unambiguously confirms the accommodation of hydride anions in the lattice, even if weak.
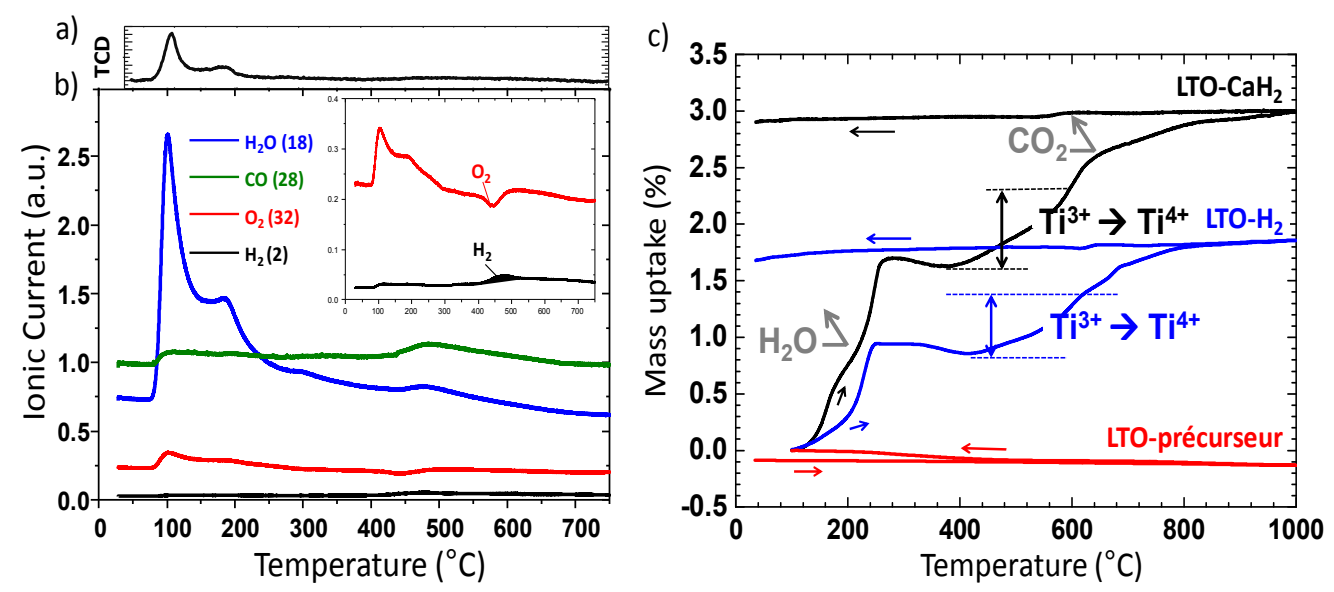
Fig 3: a) Temperature programmed desorption for $\mathrm{LTO}-\mathrm{CaH}_{2}$ under flowing $\mathrm{Ar}$ : a) $T C D$ signal. b) Mass spectrometry results for various $\mathrm{m} / \mathrm{e}$ signals. The zoom in the inset shows above $400^{\circ} \mathrm{C}$ the $\mathrm{H}_{2}$ removal together with the residual $\mathrm{O}_{2}$ consummation. c) TGA under air of the $L T O$ precursor, $L T O-C_{2} H_{2}$ and $L T O-H_{2}$ with their attribution.

$\mathrm{Ti}-\mathrm{H}$ bonds are also validated by the IR spectra given figure 2. Weak bands appear after hydridation at $1403 \mathrm{~cm}^{-1}$ for LTO, $1480 \mathrm{~cm}^{-1}$ for PTO and $1410 \mathrm{~cm}^{-1}$ for NTO. According to literature, these bands may correspond to the antisymmetric stretching vibration of the $\mathrm{Ti}-\mathrm{H}-$ Ti bridges expected around $1450 \mathrm{~cm}^{-1} .{ }^{31}$ The complete absence of any absorption in the $2000 \mathrm{~cm}^{-1}$ region of the spectra of $\mathrm{LnTO}^{-\mathrm{CaH}_{2}}$ plays against the presence of terminal Ti-H bonds, i.e. externally to the perovskite blocks. ${ }^{24}$ This is in agreement with the preferred location of the $\mathrm{Ti}^{3+}$ ions in the blocks, discussed later from our DFT modeling. Finally, another peak independent of the $\mathrm{Ln}^{3+}$ nature appears at $1625 \mathrm{~cm}^{-1}$ for the three phases. It may be assigned to $\mathrm{N}-\mathrm{H}$ bending modes, possibly resulting from residual ammonium after the methanol/ $\mathrm{NH}_{4} \mathrm{OH}$ washing stage.

It proves a minor $\mathrm{H}^{-}$incorporation compared to the recent perovskite oxyhydrides, e.g. $\operatorname{BaTi}(\mathrm{O}, \mathrm{H})_{3}{ }^{2,32}, \mathrm{CaTi}(\mathrm{O}, \mathrm{H})_{3}, \mathrm{SrTi}(\mathrm{O}, \mathrm{H})_{3}$ and the related solid solutions ${ }^{33}$ and EuTi $(\mathrm{O}, \mathrm{H})_{3} .{ }^{10} \mathrm{In}$ these phases the maximal reported $\mathrm{H}$ ratio is shown in Figure 4 as a function of the Ti-Ti distance, which proves a certain correlation. The average Ti-Ti distance of the LTO compound is situated in the same range $\left(\mathrm{d}_{\mathrm{Ti}-\mathrm{Ti}_{\mathrm{i}}}=3.926 \AA\right)$, leading to a foreseen plausible hydridation of $0.278 \mathrm{H}^{-}$per formula unit. However, in LTO the mean Ti-Ti bond distance results from a number of discrete values between 3.86 and $4.14 \AA$ due to the complex crystal structure, but the reason for such a low hydridation ratio remains open. A number of keyparameters should influence, such as the exact experimental conditions or the microstructural features of the unreacted phase. However, focusing on structural arguments, two main parameters may be responsible for the blocked $\mathrm{H}^{-}$diffusion in LnTO by comparison with other titanate oxyhydrides. a) Its fragility versus topochemical reduction taking into account reconstructive reduction in other layered terms, e.g. $\mathrm{La}_{5} \mathrm{Ti}^{+3.8}{ }_{5} \mathrm{O}_{17}$. b) Bordering $\mathrm{Ti}^{3+}$ in the layered structure are not favored, as deduced from our DFT simulations which limit the reduction ratio. c) The strongly constrained character of all Ti-O-Ti angles in LTO $\left(142^{\circ}\right.$ to $\left.174^{\circ}\right)$ compared to cubic or pseudo-cubic phases $\left(\sim 180^{\circ}\right)$ in which the overlapping with hydrogen s states via $\sigma$-bonds may be a limitation. These parameters may offer a predicting vision of the realization or not of hydridation in other next target phases. 


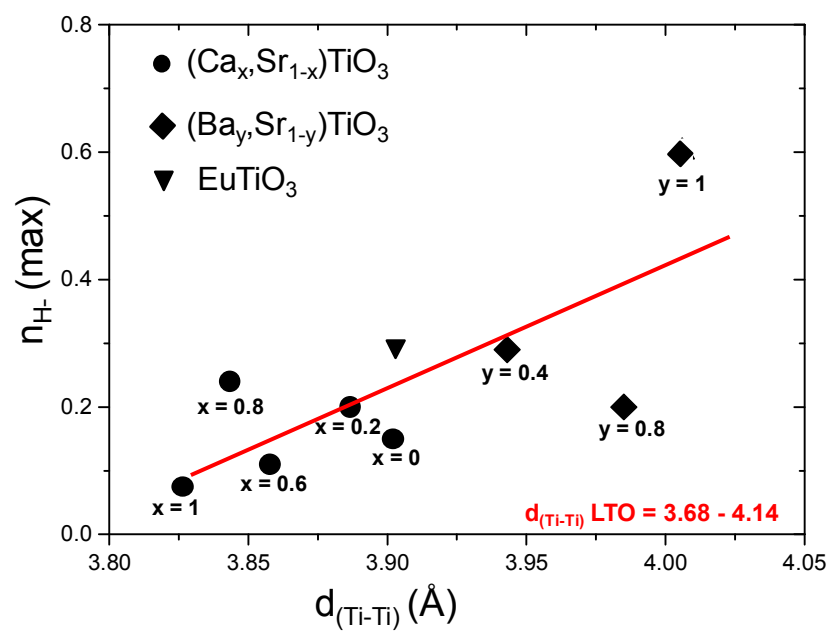

Fig 4: Plot of the maximal quantity of hydride inserted $\left(n_{H^{-}}\right.$(max)) versus the average distance Ti-Ti for several perovskite titanates: $\mathrm{BaTiO}_{3}{ }^{2}{ }^{2}, \mathrm{CaTiO}_{3}, \mathrm{SrTiO}_{3}$ and the associated solid solutions ${ }^{33}$ and $\mathrm{EuTiO}_{3}{ }^{10}$.

A rough estimation of the titanium redox can be deduced from the TGA under air for LTO$\mathrm{CaH}_{2}$ and LTO- $\mathrm{H}_{2}$ by analogy with TGA under argon, see Fig. 3b. For the pristine compound, no mass change was detected. For reduced compounds, we note the preliminary water loss already observed by TPD. It reaches $\sim 1.5 \%$ for $\mathrm{LTO}^{-\mathrm{CaH}_{2}}$. Above $400^{\circ} \mathrm{C}$, the mass uptake is assigned to $\mathrm{Ti}^{3+}$ oxidation until the inflexion at $\sim 600^{\circ} \mathrm{C}$, this latter being assigned to the removal of carbonate species. Then for both $\mathrm{LTO}-\mathrm{CaH}_{2}$ and $\mathrm{LTO}-\mathrm{H}_{2}$ the oxidation steps $(\mathrm{w} \%$ $\sim 0.7$ ) corresponds to $\sim 0.2$ oxygen, i.e. $\mathrm{La}_{2} \mathrm{Ti}_{2} \mathrm{O}_{6.8}$ for the two samples.

Neutron Diffraction: This ratio was confirmed by powder neutron diffraction (3T2 diffractometer, LLB, Saclay France). Here the preparation of one single batch (for homogeneity reasons) of $\sim 2 \mathrm{~g}$ of $\mathrm{LTO}-\mathrm{CaH}_{2}$ leads to the presence of the $\mathrm{La}_{5} \mathrm{Ti}_{5} \mathrm{O}_{17}$ secondary phase further refined to a weight ratio of $10.1(6) \%$. The main anion sub-stoichiometry $\mathrm{La}_{2} \mathrm{Ti}_{2} \mathrm{O}_{7-\delta}$ was refined to $\delta=0.27(1)$ starting from the LTO model ${ }^{34}$ (space group $\mathrm{P} 112_{1}$ ). After refinement of atomic coordinates, isotropic thermal parameters have been restrained equal for each chemical nature, due to the large number of independent atoms (i.e. four La, four $\mathrm{Ti}$ and fourteen $\mathrm{O}$ positions). It was not possible to locate the minor amount of $\mathrm{H}$ anions, while oxygen sites $\mathrm{O} 3$ to $\mathrm{O} 8$ show significant deviation from full occupancy. In the last refinement stage, their occupancies $(=91(1) \%$ ) have been restrained equal for the six concerned sites leading to the formula $\mathrm{La}_{2} \mathrm{Ti}_{2} \mathrm{O}_{6.73} \mathrm{H}_{\sim 0.02}$. The calculated vs. experimental PND diffractograms $\left(\chi^{2}=2.55, \mathrm{R}_{\mathrm{Bragg} \mathrm{LTO}-\mathrm{CaH} 2}=5.06 \%, \mathrm{R}_{\mathrm{Bragg} \text { La5Ti5017 }}=6.69 \%\right)$ are shown in Figure 5. The refined atomic coordinates, occupancies and thermal parameters are listed in Table 2. 
Atomic distances are presented in Table S6. It is striking that only the central atoms of the perovskite blocks forming Ti-O-Ti bridges in the $a b$ plane are deficient which denotes a certain anisotropy in the topochemical depletion process before the structure collapsing. It is also noteworthy that external atoms at the interlayer edges are not concerned by reduction, see Figure 6a.

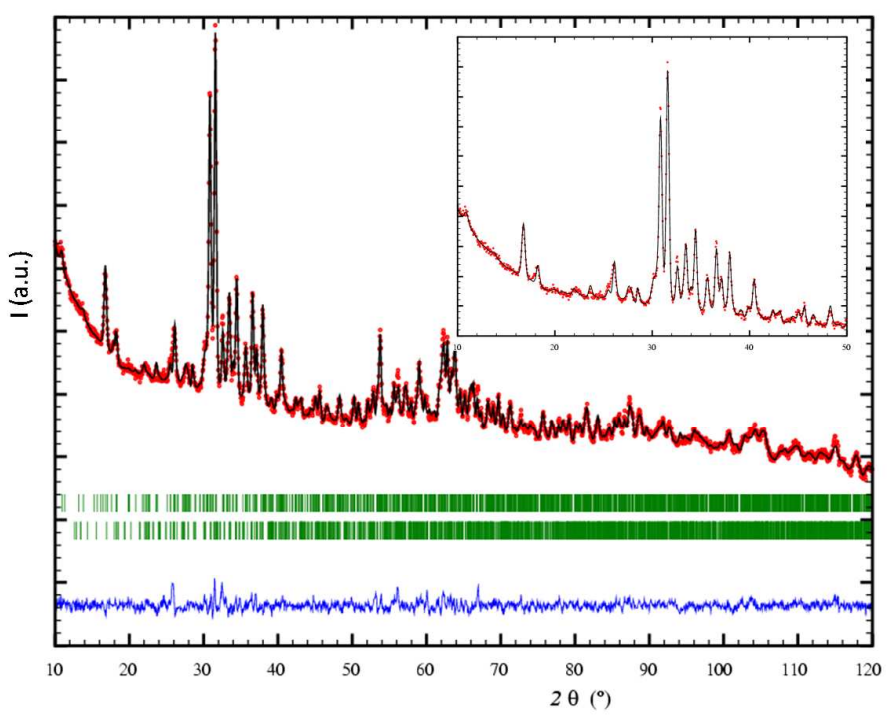

Fig 5: experimental (red) calculated (black) and difference (blue) PND pattern for $\mathrm{LTO}-\mathrm{CaH}_{2}$ with Bragg contributions of two phases (green) : $\mathrm{La}_{2} \mathrm{Ti}_{2} \mathrm{O}_{6.73}$ (top), $\mathrm{La}_{5} \mathrm{Ti}_{5} \mathrm{O}_{17}$ (bottom). The inset shows a zoom of the $10-50^{\circ}$ range.

Magnetic Properties: Quantification of $\mathrm{Ti}^{3+}$ was achieved by magnetic analysis of $\mathrm{LTO}-\mathrm{CaH}_{2}$ and $\mathrm{LTO}_{2} \mathrm{H}_{2}$. The magnetization versus external field $\mathrm{M}(\mathrm{H})$ shows predominant paramagnetism (Brillouin function shape) with similar amplitudes, see Figure 7a. Typically, $\mathrm{M}(\mathrm{H})$ of both compounds show very close moments in the main thermal range $(\sim 0.35 \mu \mathrm{B}$ at 5 Tesla and $\mathrm{T}=2 \mathrm{~K}$ ) which indicates similar paramagnetic contributions. However, their accurate interpretation is complicated owing to the nanosize of the studied sample and the presence of a weak parasitic ferromagnetic (FM) component highlighted on the low field region at $2 \mathrm{~K}, 25 \mathrm{~K}, 100 \mathrm{~K}$ and $300 \mathrm{~K}$ on the Figure $7 \mathrm{~b}$.

Indeed for both compounds, $\mathrm{M}(\mathrm{H})$ shows the opening of a small hysteresis loop at all temperatures, accompanied with a remanent moment which slightly increases on cooling. This nonzero magnetization called $\mathrm{FM}_{\text {nano }}$ hereafter was already observed and discussed for nanometric $\mathrm{BaTiO}_{3}{ }^{35}$ and $\mathrm{PbTiO}_{3}{ }^{36}$ with similar amplitudes as in the title compounds. In agreement with theoretical calculations ${ }^{37}$, it was assigned to extrinsic surficial oxygen vacancies leading to $\mathrm{Ti}^{3+}$ or $\mathrm{Ti}^{2+} \mathrm{FM}$ interactions. Then in both $\mathrm{LTO}-\mathrm{CaH}_{2}$ and $\mathrm{LTO}-\mathrm{H}_{2}$ it indicates a certain segregation of reduced species at the surface, together with the nanometrization upon reduction, leading to intrinsic weak ferromagnetic component. 


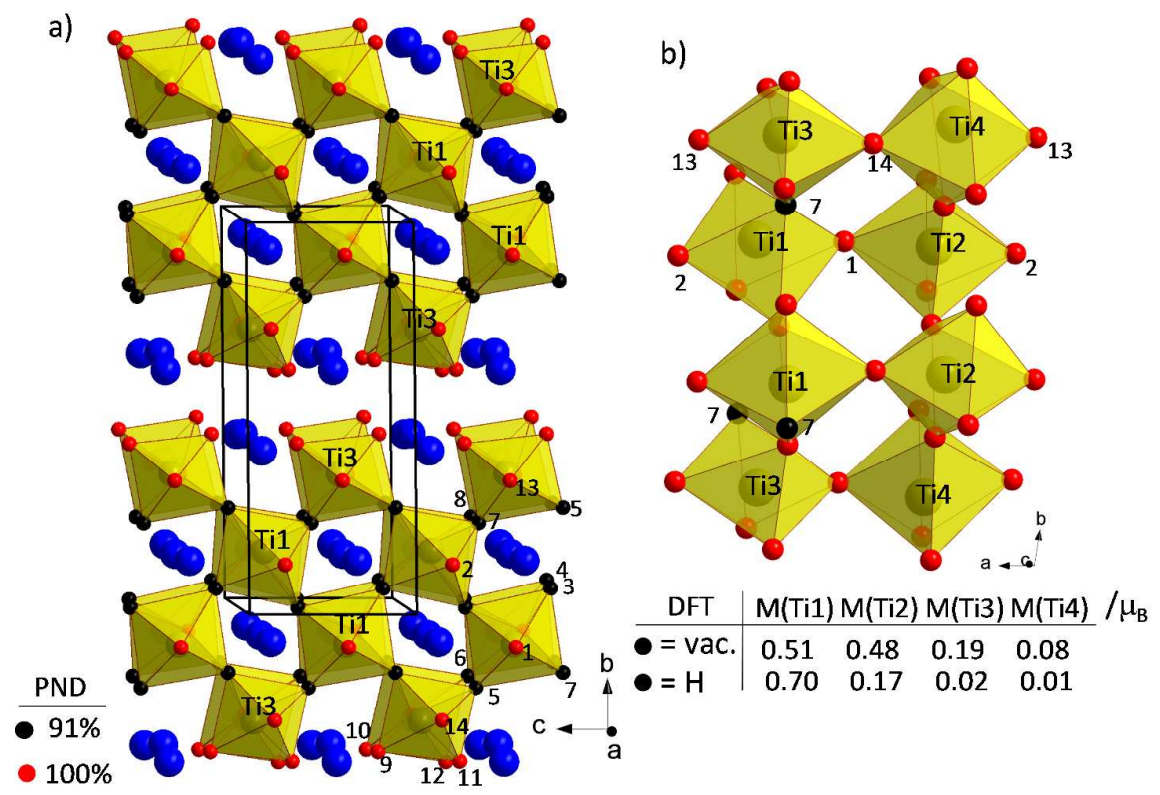

Fig 6: a) Crystal structure and atom labels for $L T O-\mathrm{CaH}_{2}$ refined from $P N D$ data. Black and red atoms correspond to partially occupied and fully occupied oxygen positions. b) Fragment of the structure used for DFT calculations with 07 (black) replaced by vacancies or $\mathrm{H}^{-}$ions. The local moment on each Ti sites is given at the bottom.

According to the non-linear $\chi^{-1}(\mathrm{~T})$ plot for $\mathrm{LTO}-\mathrm{CaH}_{2}$, its paramagnetic contribution of $\chi(\mathrm{T})$ was fitted using data collected at $200 \mathrm{Oe}, 1 \mathrm{kOe}$ and $3 \mathrm{kOe}$ between $300 \mathrm{~K}$ and $75 \mathrm{~K}$ using a modified Curie-Weiss law: $\chi=C /(T-\theta)+\chi_{0}$. Here, $C$ and $\theta$ have their usual meanings while $\chi_{0}$ takes into account both the diamagnetic and $\mathrm{FM}_{\text {nano }}$ contributions. $\chi_{0}$ is expected weak compared to the paramagnetic response and was roughly approximated to be temperature independent. It yields three comparable $\mu_{\text {eff }}$ values between 0.73 and 0.80 $\mu_{\mathrm{B}} / \mathrm{FU}$ (i.e. 0.18-0.22 $\mathrm{Ti}^{3+} / \mathrm{FU}$ assuming $1.70 \mu_{\mathrm{B}}$ per $\mathrm{Ti}^{3+}$ ion, see the EPR section below). As expected both the calculated $\theta$ and $\chi_{0}$ values depend on the applied field as long as $\mathrm{FM}_{\text {nano }}$ is not saturated. Most reliable results are expected at $\mathrm{H}=3 \mathrm{kOe}$, leading to $\theta=-30.4 \mathrm{~K}$ and $\chi_{0}=$ 1.9.10 $10^{-4} \mathrm{emu} / \mathrm{mol}$ (i.e. $1.0210^{-4} \mu_{\mathrm{B}} / \mathrm{FU}$ at $3 \mathrm{kOe}$ ). At $75 \mathrm{~K}$, an abrupt jump of the susceptibility occurs, below which the ZFC/FC divergence is pronounced. This transition is not understood yet but its amplitude suggests intrinsic spin correlations. Uncompensated or canted spin domains may occur in $\mathrm{Ti}^{3+}$ rich domains of the nano-scaled phase. We cannot exclude the contribution of a minor unidentified phase with ferromagnetic correlations in order to explain the susceptibility jump. 
Apart from its FM nano component, $\chi(T)$ for $\mathrm{LTO}^{\mathrm{H}} \mathrm{H}_{2}$ shows a predominant paramagnetic susceptibility with minor ZFC/FC divergence. The interpretation of the high temperature magnetism is complicated by the weak experimental $\chi$ values dominated by the competition between $\mathrm{FM}_{\text {nano }}$ and $\chi_{\text {dia }}$ with similar amplitudes, see $\mathrm{M}(\mathrm{H})$ at $300 \mathrm{~K}$ on Figure $7 \mathrm{a}$. This competition is such that it was not possible to extract a reasonable $\mu_{\text {eff }}$ value from the high temperature data. Assuming predominant paramagnetism in the $2-200 \mathrm{~K}$ range for $\mathrm{H}=$ $1 \mathrm{kOe}$, the fit using $\chi=\mathrm{C} /(\mathrm{T}-\theta)+\chi_{0}$ gives $\mu_{\mathrm{eff}}=0.22 \mathrm{Ti}^{3+} / \mathrm{FU}, \theta=-6.7 \mathrm{~K}$ and $\chi_{0}=7.10^{-4}$ emu/Oe.mol (i.e. $1.210^{-4} \mu_{\mathrm{B}} / \mathrm{FU}$ at $1 \mathrm{kOe}$ ).

In conclusion, both compounds show very comparable paramagnetic contributions from $\mathrm{Ti}^{3+}$ ions in relatively good agreement with the priory established $\mathrm{La}_{2} \mathrm{Ti}_{2} \mathrm{O}_{\sim 6.8} \mathrm{H}_{\delta}$ formula, if one takes into account the surficial $\mathrm{Ti}^{3+}$ species involved in $\mathrm{FM}_{\text {nano. However, the repartition }}$ of $\mathrm{Ti}^{3+}$ ions is plausibly most homogeneous in $\mathrm{LTO}^{-\mathrm{CaH}_{2}}$ (size $\sim 835 \mathrm{~nm}$ ) with strongest AFM exchanges between them compared to highly divided LTO- $\mathrm{H}_{2}$ (size $\sim 295 \mathrm{~nm}$ ). In the later, the surficial $\mathrm{Ti}^{3+}$ amount is expected biggest with more enhanced inhomogeneities between the core and the surface.
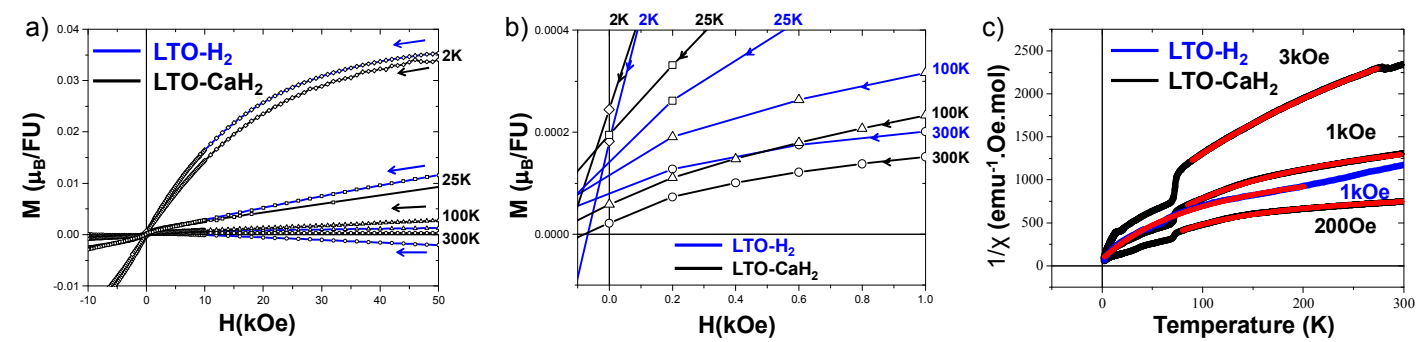

Fig 7 a) $M(H)$ magnetization plots for $L T O-H_{2}$ (blue) and $L T O-\mathrm{CaH}_{2}$ (black) on decreasing the applied field. The high-field region shows similar magnetization at $2 \mathrm{~K}$, while for $\mathrm{LTO}-\mathrm{H}_{2}$ the variation is dominated by diamagnetism at $300 \mathrm{~K}$. b) Zoom of the low field region with evidences of weak remanent moments and their variations versus $T$. c) inverse susceptibility $\chi^{-1}(T)$ at $200 \mathrm{Oe}, 1 \mathrm{kOe}$ and $3 \mathrm{kOe}$ (black) with their fit in the HT region (red). $\chi^{-1}(T)$ at $1 \mathrm{KOe}$ for $L T O-H_{2}$ fitted in the $L T$ region (red).

Electronic Structure: DFT optimizations of the precursor $\mathrm{La}_{2} \mathrm{Ti}_{2} \mathrm{O}_{7}$ and of two modified models were carried out. ${ }^{21}$ The models correspond to an oxyhydride and a lacunar phase, respectively, in which the oxygen site $\mathrm{O} 7$ is replaced by an $\mathrm{H}$ atom $\left(\mathrm{La}_{2} \mathrm{Ti}^{+3.75}{ }_{2} \mathrm{O}_{6.5} \mathrm{H}_{0.5}\right)$ or an anionic vacancy $\left(\mathrm{La}_{2} \mathrm{Ti}^{+3.5}{ }_{2} \mathrm{O}_{6.5}\right)$, see $\mathrm{Fig} 6 \mathrm{~b}$. Both modified models preserve the initial symmetry. The $\mathrm{O} 7$ site was selected because it was found partially occupied after our PND refinement. The minor structural changes between the reported LTO structure and the relaxed one validate our method, focusing on the Ti-Ti distances, see Fig S7. The two modified models give an opportunity for locally probing the effect of oxygen substitution and 
charge repartition through the analysis of DFT-calculated local moments and projected DOS for each Ti site (1 to 4). The main DOS topology is similar for the three phases, see Figure $8 \mathrm{a}-\mathrm{c}$, while the anionic modifications lead to the filling of empty Ti1 $d$ states (and Ti2 $d$ states in a lower extend) at the bottom of the conduction band (CB) giving total or partial $\mathrm{Ti}^{3+}$ character on these two sites. This is highlighted in Fig $8 \mathrm{~d}$, e in the oxyhydride case. On the opposite, Ti3 and Ti4 have their $d$ levels empty in the CB with no spin polarization in agreement with a $\mathrm{Ti}^{4+}$ states. The projected DOS for all Ti sites in LTO and its two modified forms is given Figure S8. Finally it turns out that the $\mathrm{Ti}^{4+} \rightarrow \mathrm{Ti}^{3+}$ reduction appears on sites directly in the vicinity of the $\mathrm{H}^{-}$anion or vacancy (Ti1) with an induced moment on next connected site (Ti2) within the perovskite block rather than on its edges, see Figure 6b.

For $\mathrm{La}_{2} \mathrm{Ti}_{2} \mathrm{O}_{7}$, the calculated gap is $2.6 \mathrm{eV}$. For the virtual $\mathrm{La}_{2} \mathrm{Ti}_{2} \mathrm{O}_{6.5} \mathrm{H}_{0.5}$ oxy-hydride, the $\mathrm{Hs}$ states are found in the VB, while they are unmixed with the newly occupied Ti $d$ states at the bottom of the $C B$. GGA+U with $U=3 e V$ opens a gap of $\sim 0.3 \mathrm{eV}$ for the oxy-hydride while the lacunar phase remains metallic. Compared to the real reduction rate on several $O$ sites, our models are exaggeratedly reduced and fully ordered. They give only trends for the new band structure. It is clear that partial and disordered vacancies lead in real to a distribution of occupied levels in the forbidden band, well compatible with the experimental UV-vis and IR spectral features.

Structurally, one main feature results from the replacement of $\mathrm{O} 7$ by vacancies or a $\mathrm{H}$ atom, see Figure $6 \mathrm{~b}$. In both cases it leads to the increase of the concerned Ti-X-Ti bridge distance, for instance Ti1-O7-Ti3 evolves as follows: $3.75 \AA_{\text {(oxide) }} \rightarrow 3.89 \AA_{\text {(oxyhydride) }} \rightarrow 3.98 \AA$ (lacunar). Based on this observation, the PND structure of the reduced phase might be correlated. Although not straightforward for all, some of the distances evolution refined by $\mathrm{PND}$, with respect to the experimental stoichiometric phase, can be rationalized: Ti2-O6 (90\%occ.)-Ti4 and Ti2-O8 (90\% occ.)-Ti4, $3.75 \AA \rightarrow 4.08 \AA$ and O8, $3.69 \AA \rightarrow 4.04 \AA$. 


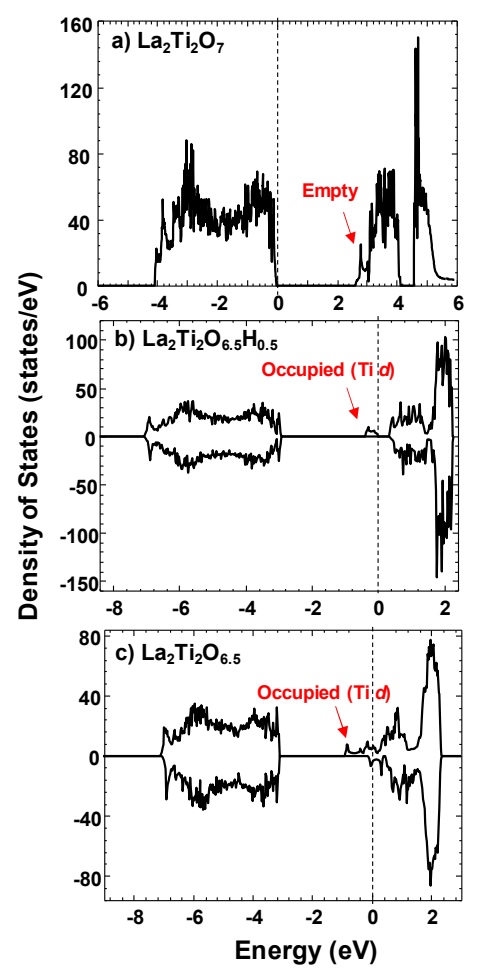

d)

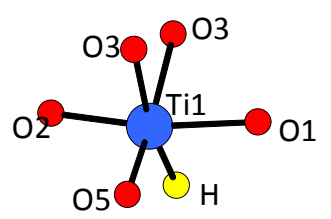

e)

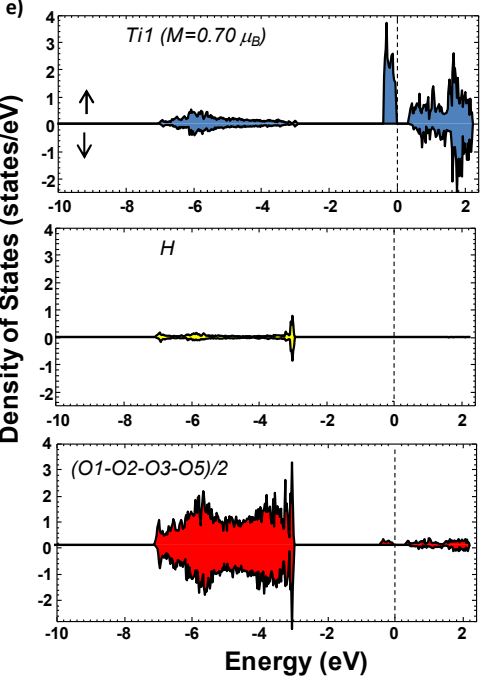

Fig 8: total density of states (GGA+U) for a) $\mathrm{La}_{2} \mathrm{Ti}_{2} \mathrm{O}_{7}(\mathrm{U}=0)$ b) $\mathrm{La}_{2} \mathrm{Ti}_{2} \mathrm{O}_{6.5} \mathrm{H}_{0.5}(\mathrm{U}=3 \mathrm{eV})$ c) $\mathrm{La}_{2} \mathrm{Ti}_{2} \mathrm{O}_{6.5}(\mathrm{U}=3 \mathrm{eV})$ with evidence of occupied defect levels at the bottom of the CB and opening of a gap for the oxyhydride. d) Ti1 case with weak overlapping between oxygen $p$ states and $\mathrm{Ti}^{3+}$ paramagnetic levels contrarily to $\mathrm{H}^{-} \mathrm{s}$ levels which show no magnetic character.

The $\mathrm{Ti}-\mathrm{H}$ bonding scheme: Further insights on the $\mathrm{Ti}^{3+}$ paramagnetic species and their possible couplings with ${ }^{1} \mathrm{H}$ nuclear spin were analyzed by EPR spectroscopy at $4 \mathrm{~K}$. LTO$\mathrm{CaH}_{2}$ displays a continuous-wave (CW) X-band EPR spectrum with an axial $\mathrm{g}$ tensor, $g_{x y}=1.95$ and $g_{z}=1.91$, characteristic of an $S=1 / 2 \mathrm{Ti}^{3+}$ species with almost quenched spinorbit coupling $\left(g_{s}=2, g_{J}=0.8\right)$, Fig 9-inset. It is in excellent agreement with the effective moment generally reported for this cation, i.e. $1.70 \mu_{B}$ weakly lower than the spin only approximation (1.74 muB) due to the negative LS contribution responsible for the weak anisotropic magnetism of this ion.

Two dimensional pulsed EPR experiments were performed to probe the nuclear environments of $\mathrm{Ti}^{3+}$ moieties. The $(+,+)$ quadrant of the HYSCORE spectrum recorded at $g_{x y}$ of the CW X-band is shown Figure 9. Along the diagonal, we can observe the nuclear Larmor frequencies with the first one centered at $1.95 \mathrm{MHz}$, the ${ }^{139} \mathrm{La}(I=7 / 2)$ Larmor frequency. It is assigned to the hyperfine coupling with ${ }^{139}$ La multi-quanta transitions. A pair of cross-peaks centered at the ${ }^{1} \mathrm{H}$ Larmor nuclear frequency, i.e. $13.7 \mathrm{MHz}$ is also revealed. The hyperfine coupling strength can be estimated from the width of the HYSCORE signals along the antidiagonal, i.e. $8 \mathrm{MHz}$ which at first sight suggests $\mathrm{Ti}-\mathrm{H}$ Fermi contact. Here, the $\mathrm{Ti}^{3+}\left(3 \mathrm{~d}^{1}\right)$ - 
$\mathrm{H}^{-}\left(\mathrm{s}^{2}\right)$ bond involves $\sigma$-overlapping with empty $d$ levels of the titanium centers. A significant electronic delocalization of the single electron probe is plausible and would largely dominate the dipolar coupling with the ${ }^{1} \mathrm{H}$ nuclear spin. We estimate that $0.5 \%$ of electronic transfer would justify by its own the $8 \mathrm{MHz}$ hyperfine coupling.

The calculations of the $\mathrm{La}_{2} \mathrm{Ti}^{+3.75}{ }_{2} \mathrm{O}_{6.5} \mathrm{H}_{0.5}$ give informative parameters about the $\mathrm{Ti}-\mathrm{H}$ electronic exchange, see Fig. $8 d$, e. Focusing on the magnetic Ti1 site $\left(M=0.7 \mu_{B}\right)$ despite direct $\mathrm{Ti}-\mathrm{H}$ bond, the newly occupied $d$ states from the bottom of the CB do not interact with $\mathrm{H} s$ states, separated by $\sim 3 \mathrm{eV}$. It is confirmed by the local moment on $\mathrm{H}$ calculated to $0.02 \mu_{B}$ (i.e. $\sim 0.02 \%$ of delocalization) which excludes any electronic transfer between the magnetic electron and the $\mathrm{H}$ site, even in our exaggerated hydrided model. It is such that the dipolar contribution with the ${ }^{1} \mathrm{H}$ nuclei is expected predominant. Assuming a point to point dipole approximation, the $8 \mathrm{MHz}$ corresponds to an electron- $\mathrm{H}$ distance of $2.14 \AA$, very close to the expected $\mathrm{Ti}^{3+}-\mathrm{H}$ distance. Finally, it is most plausible that the hyperfine coupling have both contributions in significant amount, for instance $25 \%(2 \mathrm{MHz})$ from Fermi contact in good agreement with the $\mathrm{H}$ quasi-null local moment and $75 \%(6 \mathrm{MHz})$ from dipolar interaction would correspond to Ti-H distance of $2.3 \AA$. To the best of our knowledge, despite the recent discovery of a large variety of transition metal oxyhydride, this result makes our study the first preliminary characterization of the $\mathrm{Ti}-\mathrm{H}$ electronic partition.

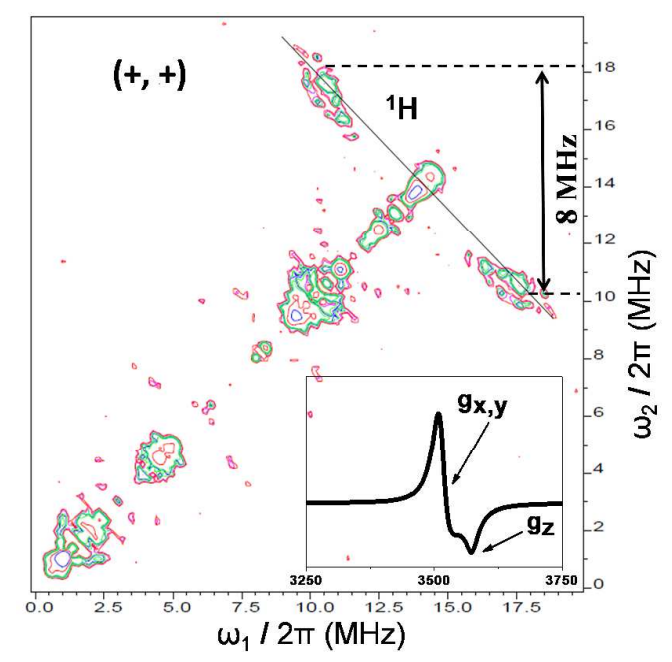

Fig 9: $(+,+)$ quadrant of the Two-dimensional EPR HYSCORE spectra recorded at $5 \mathrm{~K}$ of $L T O-\mathrm{CaH}_{2}$. It was recorded at $g_{x y}=1.95$ of the $\mathrm{Ti}^{3+}$ species. The X-band EPR spectrum is shown in the inset.

Catalytic performances: Due to its favorable bandgap and donor-doped character, $\mathrm{La}_{2} \mathrm{Ti}_{2} \mathrm{O}_{7}$ has a high photocatalytic activity for overall water splitting under UV irradiation with high quantum yields. ${ }^{38}$ Optimization of its morphology ${ }^{13}$ and surface ${ }^{39}$ area greatly improves its 
performances, while (Fe-Cr) co-doping to $\mathrm{La}_{2} \mathrm{Ti}_{2} \mathrm{O}_{7}$ narrows its bandgap, giving rise to an efficient hydrogen production under solar irradiation ${ }^{18}$. Here, the efficient photocatalytic hydrogen production and the high photocurrent in the co-doped $\mathrm{La}_{2} \mathrm{Ti}_{2} \mathrm{O}_{7}$ originate from the optimized combination of the physical-chemical properties, namely, the small bandgap and the low recombination rate of photoelectron-holes. Thus, according to its extended optical absorbance and nanometric morphologies, $\mathrm{LTO}-\mathrm{CaH}_{2}$ deserves attention as a photocathode for water-splitting. Especially, the mid-infrared bandgap, $E_{g}$ of $\sim 0.4 \mathrm{eV}$ reported above, makes it possible to reach efficiencies higher that $10 \%$ in a tandem device, if combined with a photoanode with a band gap between $0.4 \mathrm{eV}$ and $2.3 \mathrm{eV}$. Its photoelectrochemical performances have been evaluated using a three electrode cell upon linear sweep voltage in $\mathrm{pH} 7$ potassium phosphate solutions. In this preliminary study, a rough layer (ca. $300 \mu \mathrm{m}$ thick) of $\mathrm{LTO}^{-\mathrm{CaH}_{2}}$ was pasted on a FTO (Fluorine doped Tin Oxide) substrate using a commercial glazing and heated at $400^{\circ} \mathrm{C}$ under flowing argon leading to mechanically stable FTO/LTO-CaH $\mathrm{L}_{2}$ interface. It is probable that the nanotexturation of the precursor is mainly responsible for the good adherence and mechanical integrity of the layer. As shown Figure $10 \mathrm{a}$, the hydrogen evolution reaction current begins at the very low value $0.6 \mathrm{~V} v \mathrm{vs}$. RHE in the dark for our $\sim 500 \mathrm{~nm}$ thick mesoporous film, corresponding to a remarkable shift of $\sim 1 \mathrm{~V}$ vs. RHE compared to recent results reported by Paracchino et al. for an optimized photocathode ${ }^{40,41}$. This very favorable onset potential makes the $\mathrm{LTO}^{-\mathrm{CaH}_{2}}$ photoelectrode potentially compatible with previously reported photoanodes, such as $n-\mathrm{BiVO}_{4}{ }^{42}$ or $\mathrm{n}$ $\mathrm{WO}_{3}{ }^{43}$ in a complete PEC tandem cell for water splitting. At $0 \mathrm{~V}$ vs. RHE, the current density is as high as $-4 \mu \mathrm{A} / \mathrm{cm}^{2}$ in absence of any optimization of the layer. Upon illumination, the onset potential does not evolve, a small change is observed at high potential. The stability of $\mathrm{La}_{2} \mathrm{Ti}_{2} \mathrm{O}_{7}$ photocathode was tested by cycling the electrode between $+0.6 \mathrm{~V}$ to $-0.6 \mathrm{~V}$. After several cycling (typically $\sim 10$ cycles), an evolution of the J-E curve is observed, corresponding to an evolution of the samples under these conditions. Typically, the peak around $0.4 \mathrm{eV}$ may correspond to $\mathrm{Ti}^{4+}$ reduction into $\mathrm{Ti}^{3+}$. Post-mortem XRD analysis confirms a partial decomposition into $\mathrm{Ti}_{2} \mathrm{O}_{3}, \mathrm{Ti}_{6} \mathrm{O}_{11}$ and orthorhombic $\mathrm{TiO}_{2}$ during the reduction process, see Fig. 10b. However, we note a considerable increase by two decades in the photocurrent after phase degradation. This high activity could be related to the formation of heterojunction $\mathrm{TiO}_{x} / \mathrm{LaTi}_{2} \mathrm{O}_{7-\delta}$ that might be performant for water-splitting. The formation of in-situ junctions might be also an attractive pathway to explore for improved photocurrent. Another route consists in the addition of a thin $\mathrm{TiO}_{2}$ barrier to improve the stability of the electrode by avoiding parasitic reactions and degradation. 
a)

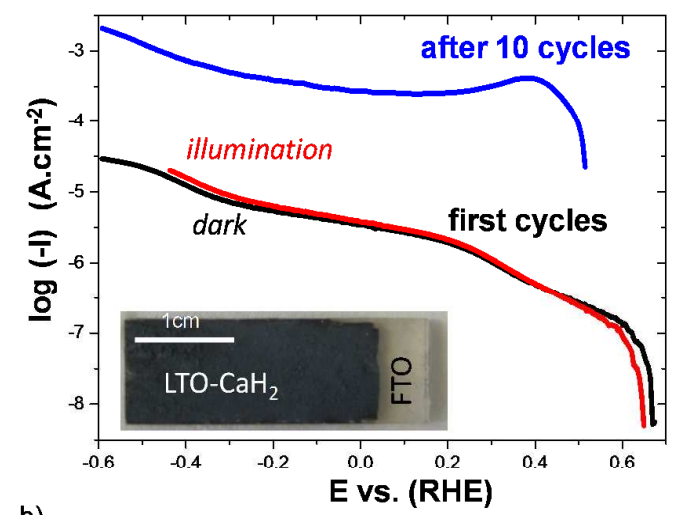

b)

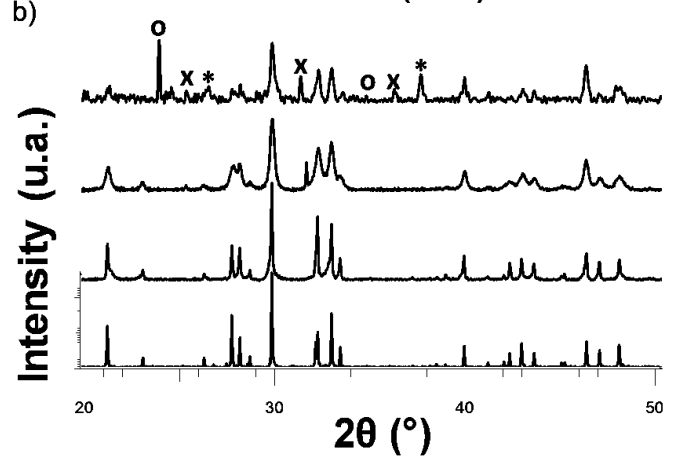

Fig 10: LTO-CaH $\mathrm{H}_{2}$ electrocatalysis for hydrogen evolution : a) Photocurrent density vs. the applied potential. First cycles in the dark (black) and under illumination (red). second test after 12 hours, in the dark (blue). A photography of the LTO film before catalytic test is also presented. b) $X R D$ Characterization of (from bottom to the top): Pristine compound LTO ; $L T O-\mathrm{CaH}_{2}$; $L T O-\mathrm{CaH}_{2}$ film before first catalytic test ; $L T O-\mathrm{CaH}_{2}$ after several catalytic tests, showing the partial decomposition into $\mathrm{Ti}_{2} \mathrm{O}_{3}$ (open circles), $\mathrm{Ti}_{6} \mathrm{O}_{11}$ (stars) and o- $\mathrm{TiO}_{2}$ (crosses).

\section{Conclusion}

In this work, we investigated topochemically modified layered perovskite $\operatorname{Ln}_{2} \mathrm{Ti}_{2} \mathrm{O}_{7-\delta}$ ( $\mathrm{Ln}=\mathrm{La}, \mathrm{Pr}, \mathrm{Nd}$ ) compounds (LTO) after reduction using either solid $\mathrm{CaH}_{2}$ (or $\mathrm{NaH}$ ) or flowing $\mathrm{H}_{2}$ (100\%). Compared to three-dimensional titanate perovskites offering well-adapted potential for the formation of oxyhydrides, it is striking that a significant nanotexturation occurs which suggests a fragility of the 2D-LTO structure upon reduction. Our results validate a limited topotactic reduction stage, prior to the reconstructive reduction into $\mathrm{La}_{5} \mathrm{Ti}^{+3.8}{ }_{5} \mathrm{O}_{17}$ observed in more sever reducing conditions, and finally into the extreme $\mathrm{LaTi}^{+3} \mathrm{O}_{3}$ polymorph. This observation may be related with the poor reducibility of titanium species located at the edge of the octahedral blocks (from our DFT simulations), which may act as a redox-barrier. However apart from $\mathrm{Ti}^{3+}$ segregation at the surface, responsible for extrinsic ferromagnetism, both reduction methods create a similar amount of oxygen vacancies close to $3 \%$. It leads to 
a band gap reduction from LTO $(3.63 \mathrm{eV})$ to the dark colored $\left.\mathrm{LTO}-\mathrm{CaH}_{2}\right)$ via occupied defect levels in the forbidden band. Similar effects are observed after treating $\mathrm{Nd}_{2} \mathrm{Ti}_{2} \mathrm{O}_{7}$ and $\mathrm{Pr}_{2} \mathrm{Ti}_{2} \mathrm{O}_{7}$.

Dealing with $\mathrm{CaH}_{2}$ as the reducing source, the weak but sensitive incorporation of $\mathrm{H}^{-}$ species in $\mathrm{LTO}-\mathrm{CaH}_{2}$ was estimated to $\mathrm{La}_{2} \mathrm{Ti}_{2} \mathrm{O}_{6.73} \mathrm{H}_{\sim 0.02}$. The understanding of parameters ruling out the hydridation appears complicated due to a number of key structural, electronic and experimental parameters, but should help predicting best candidates toward hydridation. However in $\mathrm{LTO}-\mathrm{CaH}_{2}$, the weak oxyhydride character gives the opportunity to probe the nuclear environments of $\mathrm{Ti}^{3+}$ moieties which represents to the best of our knowledge, the first preliminary characterization of the $\mathrm{Ti}-\mathrm{H}$ electronic partition. The $\mathrm{Ti}-\mathrm{H}$ covalence is mediated by non-magnetic empty $\mathrm{Ti} d$ states and no significant electron transfer occurs between $\mathrm{Ti}^{3+}$ and the hydrogen $s$ states. This result opens a broad field of investigation tuning the $\mathrm{H}$ content in more standard oxyhydrides such as $\mathrm{BaTi}(\mathrm{O}, \mathrm{H})_{3}$ for which the high $\mathrm{H}$ content $(\sim 20 \%)$ should reveal a hierarchy of Ti-H bond in the bulk. Finally the evaluation of LTO$\mathrm{CaH}_{2}$ photoelectrochemical performances shows very promising performances, in that sense that the hydrogen evolution reaction current starts as low as $+0.6 \mathrm{~V} v \mathrm{~s}$. RHE in the dark (shift of $\sim 1 \mathrm{~V}$ vs. RHE compared to recently optimized photocathodes). Although a fast degradation of the layer was observed, it makes the $\mathrm{LTO}^{-\mathrm{CaH}_{2}}$ photoelectrode potentially compatible in a complete PEC tandem cell for water splitting. At $0 \mathrm{~V} v s$. RHE, the current density is as high as $-4 \mu \mathrm{A} / \mathrm{cm}^{2}$.

\section{Supporting informations}

The supporting information is available free of charge on the ACS publication website. It includes additional spectroscopic results, details of the DFT calculations and crystallographic informations.

\section{Acknowlegement}

This work was carried out under the framework of the ANR project ANION-CO (12-JS080012). X-Ray Diffractometers are funded by Région NPDC, FEDER, CNRS and MESR. TEM facility is supported by Région NPDC, ERDF and INSU-CNRS. The CRI of Lille 1 is thanked for providing computational resources. We thank Florence Porcher and the LLB for PND data. 
Table 1: Comparison between reported powder XRD information for $L T O$ and experimental PND information for $L T O-\mathrm{CaH}_{2}$ (monoclinic system, space group: P1121)

\begin{tabular}{|c|c|c|c|c|c|}
\hline & $\begin{array}{l}\text { LTO Pristine } \\
\text { Compound }\end{array}$ & $\begin{array}{l}\text { LTO Pristine } \\
\text { X-ray Tube }\end{array}$ & $\begin{array}{c}{\mathrm{LTO} \mathrm{CaH}_{2}}_{\text {PND }}\end{array}$ & $\begin{array}{l}\mathrm{LTO} \mathrm{CaH}_{2} \\
\text { Synchrotron }\end{array}$ & $\begin{array}{l}\mathrm{LTO} \mathrm{H}_{2} \\
\text { X-ray Tube }\end{array}$ \\
\hline \multirow{4}{*}{$\begin{array}{c}\text { Unit cell ( } \AA \\
\left.\text { and }{ }^{\circ}\right)\end{array}$} & $a=7.800(3)$ & $7.8120(1)$ & $7.817(1)$ & 7.81618(1) & 7.8076(3) \\
\hline & $\mathrm{b}=13.011(4)$ & $13.0144(2)$ & $13.006(1)$ & $13.01244(3)$ & $12.9914(6)$ \\
\hline & $c=5.546(2)$ & $5.5472(9)$ & $5.547(1)$ & $5.54834(1)$ & $5.5299(3)$ \\
\hline & $\bar{a}=98.60(2)$ & $98.6318(8)$ & $98.673(2)$ & $98.6226(2)$ & $98.551(3)$ \\
\hline Volume $(\AA)^{3}$ & $556.51(34)$ & $557.59(1)$ & $557.44(2)$ & $557.930(2)$ & $554.67(3)$ \\
\hline
\end{tabular}

Table 2: Atomic positions, site occupancies and anisotropic displacement parameters from Rietveld refinement on ND data of the $\mathrm{LTO}-\mathrm{CaH}_{2}$ compound.

\begin{tabular}{|c|c|c|c|c|c|c|}
\hline Atom & Wyck. & Occ. & $x / a$ & $y / b$ & $z / c$ & Uiso \\
\hline La1 & $2 a$ & 1 & $0.280(2)$ & $0.107(1)$ & $1 / 4$ & $0.92(9)$ \\
\hline La2 & $2 a$ & 1 & $0.768(3)$ & $0.103(1)$ & $0.260(4)$ & $0.92(9)$ \\
\hline La3 & $2 a$ & 1 & $0.357(2)$ & $0.390(1)$ & $0.823(4)$ & $0.92(9)$ \\
\hline La4 & $2 a$ & 1 & $0.857(3)$ & $0.413(1)$ & $0.862(3)$ & $0.92(9)$ \\
\hline Ti1 & $2 a$ & 1 & $0.040(6)$ & $0.121(2)$ & $0.771(7)$ & $0.2(1)$ \\
\hline Ti2 & $2 a$ & 1 & $0.506(4)$ & $0.107(3)$ & $0.788(7)$ & $0.2(1)$ \\
\hline Ti3 & $2 a$ & 1 & $0.084(5)$ & $0.320(2)$ & $0.325(6)$ & $0.2(1)$ \\
\hline Ti4 & $2 a$ & 1 & $0.578(6)$ & $0.338(2)$ & $0.293(5)$ & $0.2(1)$ \\
\hline 01 & $2 a$ & 1 & $0.776(3)$ & $0.117(1)$ & $0.796(4)$ & $0.12(6)$ \\
\hline 02 & $2 a$ & 1 & $0.280(4)$ & $0.096(1)$ & $0.678(4)$ & $0.12(6)$ \\
\hline 03 & $2 a$ & $0.907(2)$ & $0.033(3)$ & $0.025(1)$ & $0.059(4)$ & $0.12(6)$ \\
\hline 04 & $2 a$ & $0.907(2)$ & $0.476(3)$ & $0.023(2)$ & $0.001(4)$ & $0.12(6)$ \\
\hline 05 & $2 a$ & $0.907(2)$ & $0.102(3)$ & $0.234(2)$ & $0.991(5)$ & $0.12(6)$ \\
\hline 06 & $2 a$ & $0.907(2)$ & $0.533(3)$ & $0.222(2)$ & $0.973(5)$ & $0.12(6)$ \\
\hline 07 & $2 a$ & $0.907(2)$ & $0.015(3)$ & $0.192(2)$ & $0.482(4)$ & $0.12(6)$ \\
\hline 08 & $2 a$ & $0.907(2)$ & $0.548(4)$ & $0.187(1)$ & $0.458(4)$ & $0.12(6)$ \\
\hline 09 & $2 a$ & 1 & $0.109(4)$ & $0.398(1)$ & $0.577(4)$ & $0.12(6)$ \\
\hline 010 & $2 a$ & 1 & $0.633(3)$ & $0.415(1)$ & $0.570(4)$ & $0.12(6)$ \\
\hline 011 & $2 a$ & 1 & $0.122(3)$ & $0.423(2)$ & $0.088(5)$ & $0.12(6)$ \\
\hline 012 & $2 a$ & 1 & $0.599(3)$ & $0.444(1)$ & $0.101(4)$ & $0.12(6)$ \\
\hline 013 & $2 a$ & 1 & $0.324(3)$ & $0.312(1)$ & $0.338(5)$ & $0.12(6)$ \\
\hline 014 & $2 a$ & 1 & $0.823(3)$ & $0.306(1)$ & $0.235(4)$ & $0.12(6)$ \\
\hline
\end{tabular}


1. Masuda, N.; Kobayashi, Y.; Hernandez, O.; Bataille, T.; Paofai, S.; Suzuki, H.; Ritter, C.; Ichijo, N.; Noda, Y.; Takegoshi, K.; Tassel, C.; Yamamoto, T.; Kageyama, H., Hydride in BaTiO2.5H0.5: A Labile Ligand in Solid State Chemistry. Journal of the American Chemical Society 2015, 137, 15315-15321.

2. Yajima, T.; Kitada, A.; Kobayashi, Y.; Sakaguchi, T.; Bouilly, G.; Kasahara, S.; Terashima, T.; Takano, M.; Kageyama, H., Epitaxial Thin Films of ATiO(3-x)H(x) (A = Ba, Sr, Ca) with Metallic Conductivity. Journal of the American Chemical Society 2012, 134, 8782-8785.

3. Bouilly, G.; Yajima, T.; Terashima, T.; Yoshimune, W.; Nakano, K.; Tassel, C.; Kususe, Y.; Fujita, K.; Tanaka, K.; Yamamoto, T.; Kobayashi, Y.; Kageyama, H., Electrical Properties of Epitaxial Thin Films of Oxyhydrides ATiO(3-x)H(x) (A = Ba and Sr). Chemistry of Materials 2015, 27, 6354-6359.

4. Kim, I. S.; Itoh, M.; Nakamura, T., Electrical conductivity and non metal transition in the perovskite-related layered system $\mathrm{Ca}_{n+1} \mathrm{Ti}_{n} \mathrm{O}_{3 n+1-\delta}(\mathrm{n}=2,3$, and $\infty)$. Journal of Solid State Chemistry 1992, 101, 77-86.

5. Nanot, M.; Queyroux, F.; Gilles, J. C.; Carpy, A.; Galy, J., Multiple Phases in systems $\mathrm{Ca}_{2} \mathrm{Nb}_{2} \mathrm{O} 7-$ $\mathrm{NaNbO}_{3} \mathrm{AND} \mathrm{La}_{2} \mathrm{Ti}_{2} \mathrm{O}_{7}-\mathrm{CaTiO}_{3}$ - homologons series into formula $\mathrm{ABO}_{3 n+2}$. Journal of Solid State Chemistry 1974, 11, 272-284.

6. Lichtenberg, F.; Herrnberger, A.; Wiedenmann, K.; Mannhart, J., Synthesis of perovskiterelated layered $\mathrm{A}(\mathrm{n}) \mathrm{B}(\mathrm{n}) \mathrm{O}(3 \mathrm{n}+2)=\mathrm{ABO}(\mathrm{x})$ type niobates and titanates and study of their structural, electric and magnetic properties. Progress in Solid State Chemistry 2001, 29, 1-70.

7. Shao, Z. M.; Saitzek, S.; Roussel, P.; Desfeux, R., Stability limit of the layered-perovskite structure in $\mathrm{Ln}(2) \mathrm{Ti}(2) \mathrm{O}$ (7) ( $\mathrm{Ln}=$ lanthanide) thin films grown on (110)-oriented SrTiO3 substrates by the sol-gel route. Journal of Materials Chemistry 2012, 22, 24894-24901.

8. Blundred, G.D.; Bridges, C. Bridges; Rosseinsky, M.J., New Oxidation States and Defect Chemistry in the Pyrochlore Structure. Angew.Chem. Int. Ed., 2004, 43, 3562-3565.

9. Hayward, M., Phase separation during Phase Separation during the Topotactic Reduction of the Pyrochlore $\mathrm{Y}_{2} \mathrm{Ti}_{2} \mathrm{O}_{7}$ Chem. Mater. 2005, 17, 670-675

10. Yamamoto, T.; Yoshii, R.; Bouilly, G.; Kobayashi, Y.; Fujita, K.; Kususe, Y.; Matsushita, Y.; Tanaka, K.; Kageyama, H., An Antiferro-to-Ferromagnetic Transition in EuTiO3-xHx Induced by Hydride Substitution. Inorganic Chemistry 2015, 54, 1501-1507.

11. Gong, G. S.; Qiu, Y.; Zerihun, G.; Fang, Y. J.; Yin, C. Y.; Zhu, C. M.; Huang, S.; Yuan, S. L., Multiferroic properties in transition metals doped $\mathrm{La}_{2} \mathrm{Ti}_{2} \mathrm{O}_{7}$ ceramics. Journal of Alloys and Compounds 2014, 611, 30-33.

12. Zhang, J. Y.; Dang, W. Q.; Ao, Z. M.; Cushing, S. K.; Wu, N. Q., Band gap narrowing in nitrogendoped La2Ti2O7 predicted by density-functional theory calculations. Physical Chemistry Chemical Physics 2015, 17, 8994-9000.

13. Kim, H. G.; Hwang, D. W.; Bae, S. W.; Jung, J. H.; Lee, J. S., Photocatalytic water splitting over $\mathrm{La}_{2} \mathrm{Ti}_{2} \mathrm{O}_{7}$ synthesized by the polymerizable complex method. Catalysis Letters 2003, 91, 193-198.

14. Ku, Y.; Wang, L. C.; Ma, C. M., Photocatalytic oxidation of isopropanol in aqueous solution using perovskite-structured $\mathrm{La}_{2} \mathrm{Ti}_{2} \mathrm{O}_{7}$. Chemical Engineering \& Technology 2007, 30, 895-900.

15. Yang, Q. L.; Kang, S. Z.; Chen, H.; Bu, W. B.; Mu, J., La2Ti2O7: An efficient and stable photocatalyst for the photoreduction of $\mathrm{Cr}(\mathrm{VI})$ ions in water. Desalination 2011, 266, 149-153.

16. Wang, Q.; Hisatomi, T.; Moriya, Y.; Maeda, K.; Domen, K., Physicochemical properties and photocatalytic $\mathrm{H}-2$ evolution activity of $\mathrm{Rh}$-doped $\mathrm{La}_{2} \mathrm{Ti}_{2} \mathrm{O}_{7}$ prepared by molten salt synthesis. Catalysis Science \& Technology 2013, 3, 2098-2103.

17. Hwang, D. W.; Kirn, H. G.; Lee, J. S.; Kim, J.; Li, W.; Oh, S. H., Photocatalytic hydrogen production from water over m-doped $\mathrm{La}_{2} \mathrm{Ti}_{2} \mathrm{O}_{7}(\mathrm{M}=\mathrm{Cr}$, Fe) under visible light irradiation (lambda > $420 \mathrm{~nm})$. Journal of Physical Chemistry B 2005, 109, 2093-2102.

18. Hu, S. J.; Jia, L. C.; Chi, B.; Pu, J.; Jian, L., Visible light driven (Fe, Cr)-codoped $\mathrm{La}_{2} \mathrm{Ti}_{2} \mathrm{O}_{7}$ photocatalyst for efficient photocatalytic hydrogen production. Journal of Power Sources 2014, 266, 304-312.

19. Meng, F. K.; Li, J. T.; Hong, Z. L.; Zhi, M. J.; Sakla, A.; Xiang, C. C.; Wu, N. Q., Photocatalytic generation of hydrogen with visible-light nitrogen-doped lanthanum titanium oxides. Catalysis Today 2013, 199, 48-52. 
20. Joseph, L. K.; Dayas, K. R.; Damodar, S.; Krishnan, B.; Krishnankutty, K.; Nampoori, V. P. N.; Radhakrishnan, R., Photoluminescence studies on rare earth titanates prepared by self-propagating high temperature synthesis method. Spectrochimica Acta Part a-Molecular and Biomolecular Spectroscopy 2008, 71, 1281-1285.

21. Kresse, G.; Furthmüller, J., Vienna Ab-initio Simulation Package (VASP); Institut fûr Materialphysik: Vienna (http://www.vasp.at/), 2012. 2012.

22. Perdew, J. P.; Wang, Y., ACCURATE AND SIMPLE ANALYTIC REPRESENTATION OF THE ELECTRON-GAS CORRELATION-ENERGY. Physical Review B 1992, 45, 13244-13249.

23. Kresse, G.; Joubert, D., From ultrasoft pseudopotentials to the projector augmented-wave method. Physical Review B 1999, 59, 1758-1775.

24. Dudarev, S. L.; Botton, G. A.; Savrasov, S. Y.; Humphreys, C. J.; Sutton, A. P., Electron-energyloss spectra and the structural stability of nickel oxide: An LSDA+U study. Physical Review B 1998, 57, 1505-1509.

25. RodriguezCarvajal, J., Fullprof, http://www.ill.eu/sites/fullprof/, 2001. 2001.

26. Retoux, R.; Rodriguez-Carvajal, J.; Lacorre, P., Neutron diffraction and TEM studies of the crystal structure and defects of $\mathrm{Nd}_{4} \mathrm{Ni}_{3} \mathrm{O}_{8}$. Journal of Solid State Chemistry 1998, 140, 307-315.

27. Poltavets, V. V.; Lokshin, K. A.; Egami, T.; Greenblatt, M., The oxygen deficient RuddlesdenPopper $\mathrm{La}_{3} \mathrm{Ni}_{2} \mathrm{O}_{7-\delta}$ (delta=0.65) phase: Structure and properties. Materials Research Bulletin 2006, 41, 955-960.

28. Wang, F.; Qian, X. Q.; Li, X. W.; Ye, J. K.; Han, Z.; Chen, Y. X.; Liu, G. H.; Li, J. T., Optical-thermal properties of reduced $\mathrm{TiO}_{2}$ microspheres prepared by flame spraying. Materials Letters 2015, 151, 82-84.

29. Becker, K. D.; Schrader, M.; Kwon, H. S.; Yoo, H. I., Electrical and optical characterization of undoped $\mathrm{BaTiO}_{3}$ in the quenched state. Physical Chemistry Chemical Physics 2009, 11, 3082-3089.

30. Munir, S.; Shah, S. M.; Hussain, H.; Khan, R. A., Effect of carrier concentration on the optical band gap of $\mathrm{TiO}_{2}$ nanoparticles. Materials \& Design 2016, 92, 64-72.

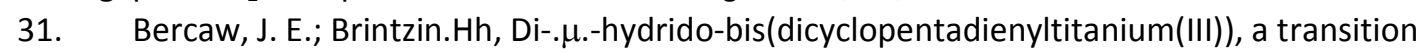
metal complex with a diborane-like double hydrogen bridge . Journal of the American Chemical Society 1969, 91, 7301-7306.

32. Kobayashi, Y.; Hernandez, O. J.; Sakaguchi, T.; Yajima, T.; Roisnel, T.; Tsujimoto, Y.; Morita, M.; Noda, Y.; Mogami, Y.; Kitada, A.; Ohkura, M.; Hosokawa, S.; Li, Z. F.; Hayashi, K.; Kusano, Y.; Kim, J. E.; Tsuji, N.; Fujiwara, A.; Matsushita, Y.; Yoshimura, K.; Takegoshi, K.; Inoue, M.; Takano, M.; Kageyama, $\mathrm{H}$., An oxyhydride of $\mathrm{BaTiO}_{3}$ exhibiting hydride exchange and electronic conductivity. Nature Materials 2012, 11, 507-511.

33. Sakaguchi, T.; Kobayashi, Y.; Yajima, T.; Ohkura, M.; Tassel, C.; Takeiri, F.; Mitsuoka, S.; Ohkubo, H.; Yamamoto, T.; Kim, J. E.; Tsuji, N.; Fujihara, A.; Matsushita, Y.; Hester, J.; Avdeev, M.; Ohoyama, K.; Kageyama, $\mathrm{H}$., Oxyhydrides of $(\mathrm{Ca}, \mathrm{Sr}, \mathrm{Ba}) \mathrm{TiO}_{3}$ Perovskite Solid Solutions. Inorganic Chemistry 2012, 51, 11371-11376.

34. Gasperin, M., Lanthanum dititatnate. Acta Crystallographica Section B-Structural Science 1975, 31, 2129-2130.

35. Ramakanth, S.; Hamad, S.; Rao, S. V.; Raju, K. C. J., Magnetic and nonlinear optical properties of $\mathrm{BaTiO}_{3}$ nanoparticles. Aip Advances 2015, 5, 11.

36. Bhatti, H. S.; Hussain, S. T.; Khan, F. A.; Hussain, S., Synthesis and induced multiferroicity of perovskite PbTiO3; a review. Applied Surface Science 2016, 367, 291-306.

37. Bahoosh, S. G.; Trimper, S.; Wesselinowa, J. M., Origin of ferromagnetism in $\mathrm{BaTiO}_{3}$ nanoparticles. Physica Status Solidi-Rapid Research Letters 2011, 5, 382-384.

38. Kim, J.; Hwang, D. W.; Kim, H. G.; Bae, S. W.; Ji, S. M.; Lee, J. S., Nickel-loaded $\mathrm{La}_{2} \mathrm{Ti}_{2} \mathrm{O}_{7}$ as a bifunctional photocatalyst. Chemical Communications 2002, , 2488-2489.

39. Onozuka, K.; Kawakami, Y.; Imai, H.; Yokoi, T.; Tatsumi, T.; Kondo, J. N., Perovskite-type $\mathrm{La}_{2} \mathrm{Ti}_{2} \mathrm{O}_{7}$ nriesoporous photocatalyst. Journal of Solid State Chemistry 2012, 192, 87-92. 
40. Paracchino, A.; Laporte, V.; Sivula, K.; Gratzel, M.; Thimsen, E., Highly active oxide photocathode for photoelectrochemical water reduction. Nature Materials 2011, 10, 456-461. 41. Hsu, Y. K.; Yu, C. H.; Lin, H. H.; Chen, Y. C.; Lin, Y. G., Template synthesis of copper oxide nanowires for photoelectrochemical hydrogen generation. Journal of Electroanalytical Chemistry 2013, 704, 19-23.

42. Abdi, F. F.; Han, L. H.; Smets, A. H. M.; Zeman, M.; Dam, B.; van de Krol, R., Efficient solar water splitting by enhanced charge separation in a bismuth vanadate-silicon tandem photoelectrode. Nature Communications 2013, 4, 7.

43. Amano, F.; Li, D.; Ohtani, B., Fabrication and photoelectrochemical property of tungsten(VI) oxide films with a flake-wall structure. Chemical Communications 2010, 46, 2769-2771.

\section{TOC Graphic}

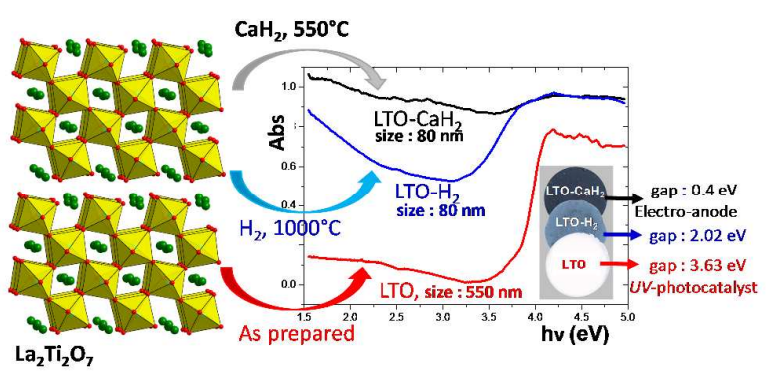

